\title{
Simulation of Temperature Distribution And Heat Generation During Dissimilar Friction Stir Welding Of AA6061 Aluminum Alloy and Al-Mg2Si Composite
}

\section{Ebtesam Sharghi}

Amirkabir University of Technology

Ali Farzadi ( $\sim$ farzadi@aut.ac.ir)

Amirkabir University of Technology

\section{Research Article}

Keywords: Modeling, CFD, Volume of fraction (VOF) method, Rotational speed, Material flow, Thermal cycle

Posted Date: May 6th, 2021

DOl: https://doi.org/10.21203/rs.3.rs-465175/v1

License: (c) (1) This work is licensed under a Creative Commons Attribution 4.0 International License. Read Full License

Version of Record: A version of this preprint was published at The International Journal of Advanced Manufacturing Technology on October 11th, 2021. See the published version at https://doi.org/10.1007/s00170-021-08175-z. 


\section{Simulation of temperature distribution and heat generation}

\section{during dissimilar friction stir welding of AA6061 aluminum alloy and $\mathrm{Al}-\mathrm{Mg}_{2} \mathrm{Si}$ composite}

Ebtesam Sharghi, Ali Farzadi*

Department of Materials and Metallurgical Engineering, Amirkabir University of Technology (Tehran Polytechnic), Hafez Ave, Valiasr Sq, Postcode: 15916-34311, Tehran, Iran

* Corresponding Author: Assistant Professor, Department of Materials and Metallurgical Engineering, Amirkabir University of Technology (Tehran Polytechnic), No 350, Hafez Ave, Valiasr Sq, Postcode: 15916-34311, Tehran, Iran, PO Box: 15875-4413, Email: farzadi@aut.ac.ir, Tel: +98 21 64542928, Fax: +98 21 66967408, Mobile: +98 9122279691. 


\begin{abstract}
During dissimilar friction stir welding (FSW) of Al-Mg $2 \mathrm{Si}$ metal matrix composite and AA6061 aluminum alloy, the temperature field and heat generation were investigated using a 3-dimensional computational fluid dynamics (CFD) model and FLUENT software. The simulations were conducted for rotational speeds of 720, 920 and 1120 rpm. The welding experiments were carried out to validate the simulation results. About 70 per cent of the heat generates at the interface between the shoulder and the workpiece. The maximum temperature was predicted on the advancing side (AS). The difference between the peak temperatures on the AS and the retreating side (RS) was about $115 \mathrm{~K}$. The effect of the rotational speed on the peak temperature is significant. The temperature distribution in the cross-sections is asymmetric, which originates from different material velocities on the AS and RS. The peak temperature on the RS develops under the top surface, while the peak temperature on the AS develops on the surface.
\end{abstract}

Keywords: Modeling, CFD, Volume of fraction (VOF) method, Rotational speed, Material flow, Thermal cycle.

\title{
1. Introduction
}

In recent decades, friction stir welding (FSW), a solid-state technique, has been highly considered due to its advantages over fusion welding methods. This welding method is a green technology and has high energy efficiency. During FSW, joints are produced without volume melting and with no need for filler metal. Hence, there is no concern about chemical composition compatibility $[1,2]$. This feature makes it easier to join dissimilar materials with multiple applications in the automotive and aerospace industries because of their high performance and low weight [3]. The joint of an alloy 
and a metal matrix composite (MMC) is one kind of useful dissimilar joints. The potential properties such as high strength and low density can be applied using a dissimilar joints in the critical parts. Hence, efficiency will improve, and costs will reduce $[4]$.

Among the MMCs, $\mathrm{Al}-\mathrm{Mg}_{2} \mathrm{Si}$ is an ultra-light composite reinforced with the $\mathrm{Mg}_{2} \mathrm{Si}$ insitu phase. The mechanical properties of these composites can be improved by heat treatment. Because the $\mathrm{Mg}_{2} \mathrm{Si}$ intermetallic compound has low density, high melting temperature, and low thermal expansion coefficient, $\mathrm{Al}-\mathrm{Mg}_{2} \mathrm{Si}$ is a proper choice to replace cast iron and steel in various industries such as automotive. Therefore, The Al$\mathrm{Mg}_{2} \mathrm{Si}$ composite is an appropriate candidate to make a dissimilar joint with aluminum alloys [5, 6]. A dissimilar joint between a MMC and a metal alloy using FSW can be adequately made because of the elimination of the fusion welding defects, e.g. porosities, segregations and solidification cracks [7].

In this process, the heat is generated using a non-consumable rotating tool. The tool enters the interface of the workpieces. Then, the tool rotation leads to the friction of materials and the flow of them. In addition to frictional heating, a part of the heat is produced by converting mechanical energy into thermal energy. The heat generated by friction and deformation is required to soften the materials. The rotation of the tool transfers the materials to the back of the shoulder, and this process finally causes a solidstate joint between two base materials $[8,9]$.

The details of the heat generation and the temperature field in FSW play an essential role in process understanding, tool optimization, and estimation of post-welded structure and properties [10]. Thus, some attempts were made to study the effect of welding variables on the temperature field and heat generation in the FSW process of similar and dissimilar materials.

Lakshminarayanan et al. [11] studied the generated heat and welding defects during the joining of the RDE-40 aluminum alloy. Their results showed that at lower welding speeds than $22 \mathrm{~mm} / \mathrm{min}$, pinhole type defects observed because of the increase in the heat input per weld unit length. Also, at welding speeds above $75 \mathrm{~mm} / \mathrm{min}$, tunnel 
defects have been observed on the retreating side (RS), which results from the low heat input. Tang et al. [12] carried out research on the effect of the tool rotational speed on the temperature distribution and heat input during welding of AA6061 aluminum alloy using gauges of K-type thermocouples located in the different points of the workpieces. When the rotational speed increased from 300 to $650 \mathrm{rpm}$, the peak temperature rose about $40{ }^{\circ} \mathrm{C}$ and more heat produced in the welding zone.

Mechanical heat generation, transport of heat and mass, great strain and high strain rate make the concept of the FSW process complex to comprehend. On the other hand, it is challenging to study the details experimentally. For instance, the measurement of temperature at the stir zone, which locates under the shoulder, is almost impossible. This is because of the material flow in this area, which can lead to the breaking or movement of thermocouples. Also, the experimental studying of material flow using the marker method indicates only the information of the primary and final position of the material [13]. Therefore, the FSW process simulation makes it easier to understand the heat and temperature distribution and reduces the costs and eases the optimization of the parameters [14]. For these reasons, researchers use simulation to study FSW in recent years. Nandan et al. [15] simulated the heat generation and the temperature fields of AA6061 aluminum alloy in FSW. They considered the contact condition as a partial sticking and completely sticking at the tool shoulder and pin interface, respectively. Their results showed that the pin generates less heat because of the smaller radius and the low relative speed between the pin and the workpiece. Chen et al. [16] reviewed thermo-mechanical analyses used for simulation of FSW. They reviewed both computational fluid dynamics (CFD) and computational solid mechanics (CSM). They believed that the mesh size should be improved to better understand heat generation and temperature distribution during the process. Also, Chen et al. [17] simulated FSW using a frictional boundary condition on the basis of the Coulomb friction model. By using this condition, they considered a non-uniform contact interface between tool and workpieces. The other study [18] explored the temperature fields and material flow in FSW of AA7A52 alloy. They compared the results with the results obtained from a model with a smooth pin and validated the simulation results with the experiment data. 
They concluded that both smooth and threaded pin generates an identical temperature distribution, and the pin thread has no significant effect on the temperature fields. While the flow velocity, strain rate, vertical pressure, and the flow pattern of materials in the stir zone are maily affected by the threaded pin. Zhi et al. [19] examined the effect of the tool tilt angle on the material flow and heat generation using a CFD model and experimental tests. Their results showed when the tilt angle is $2.5^{\circ}$, the heat generation at the workpiece interface and tool has a more dominant role, and the area with higher temperature expands on the advancing side (AS). Yang et al. [20] extended a threedimensional (3D) model to explore the heat and mass transfer during dissimilar FSW joint of $\mathrm{Mg}$ and $\mathrm{Al}$ alloys. Also, they used the volume of fraction (VOF) method to study each phase distribution. There was good accordance between the measured and prediction results of thermal cycles.

Arora et al. [21] proposed a model that computes the fields of temperature, velocity and torque for shoulders with different diameters. The results showed that the peak temperature at a constant speed increases with the increasing shoulder diameter. Zhang et al. [22] carried out a CFD simulation, which considered an incomplete contact between the workpiece and tool to evaluate the material flow pattern and the heat generation. Their results showed that the high temperature occurs on the AS, and the temperature distribution is asymmetric by using the tilt tool. The frictional force and material stirring near the tool improve significantly, resulting in proper welds formation. Chen et al. [23] applied a 3D CFD model to investigate the retractable pin tool FSW (RPT-FSW) process. The average temperature decreases about $10^{\circ} \mathrm{C}$ during RPT-FSW, compared with the conventional FSW. The experimental data support the calculated temperature distribution and the geometry of the deformed area.

In order to study the heat generation in dissimilar joints, Kishore et al. [24] used a 2D model to predict the temperature fields in the joints of AA2024-AA7075 and AA6061AA5083 aluminum alloys using the Fluent software. They observed that the maximum temperature generates at the material with more hardness because of the viscous dissipation. The position of the materials on the retreating or advancing sides does not affect the peak temperature. Zhang et al. [25] presented a new thermo-mechanical CFD 
model to explore the heat flux distribution. They concluded that there is a complex sticking/sliding state at the tool and workpiece interface. The maximum part of the frictional heat generates at the shoulder periphery. Padmanaban et al. [26] studied the dissimilar joint of AA7075-AA2024 aluminum alloys using a CFD model. This study showed that the temperature distribution is asymmetrical, and the maximum temperature, which decreases with increasing the welding speed, is about 80 to $90 \%$ of the base metal melting point. Gotawala et al. [27] analyzed the material flow and temperature distribution patterns during dissimilar joint of Al1050 and copper. They used the VOF method and found that the temperature distributes asymmetrically around the weld centerline. Also, the material distribution pattern was comparable with experimental cross-section macrographs.

According to the above literature survey, the dissimilar joints between an alloy and a composite have been rarely studied. Besides, the simulation and the heat transfer in FSW are significant for better understanding. Therefore, the temperature fields and heat generation in the dissimilar joint of AA6061 aluminum alloy and $\mathrm{Al}-\mathrm{Mg}_{2} \mathrm{Si} \mathrm{MMC}$ were simulated in this study. Besides, the comparison of the simulation results with the experimental data is carried out. The VOF approach using the Fluent software was used to calculate the material distribution, which plays an essential role in heat transfer.

\section{Numerical modeling}

During the FSW process, the heat is produced at a constant rate; hence, the transport phenomena during the FSW process can be considered a steady-state problem, except at the beginning and the end of the process. Also, the material flow is defined as a viscoplastic, incompressible, and non-Newtonian flow [15]. The simulation of the process is done using the ANSYS Fluent 16.1 commercial software, which worked based on the $\mathrm{CFD}$ and the finite volume method. The $3 \mathrm{D}$ geometrical model, including the workpieces and tool, with dimensions in mm is illustrated in Figure 1. 


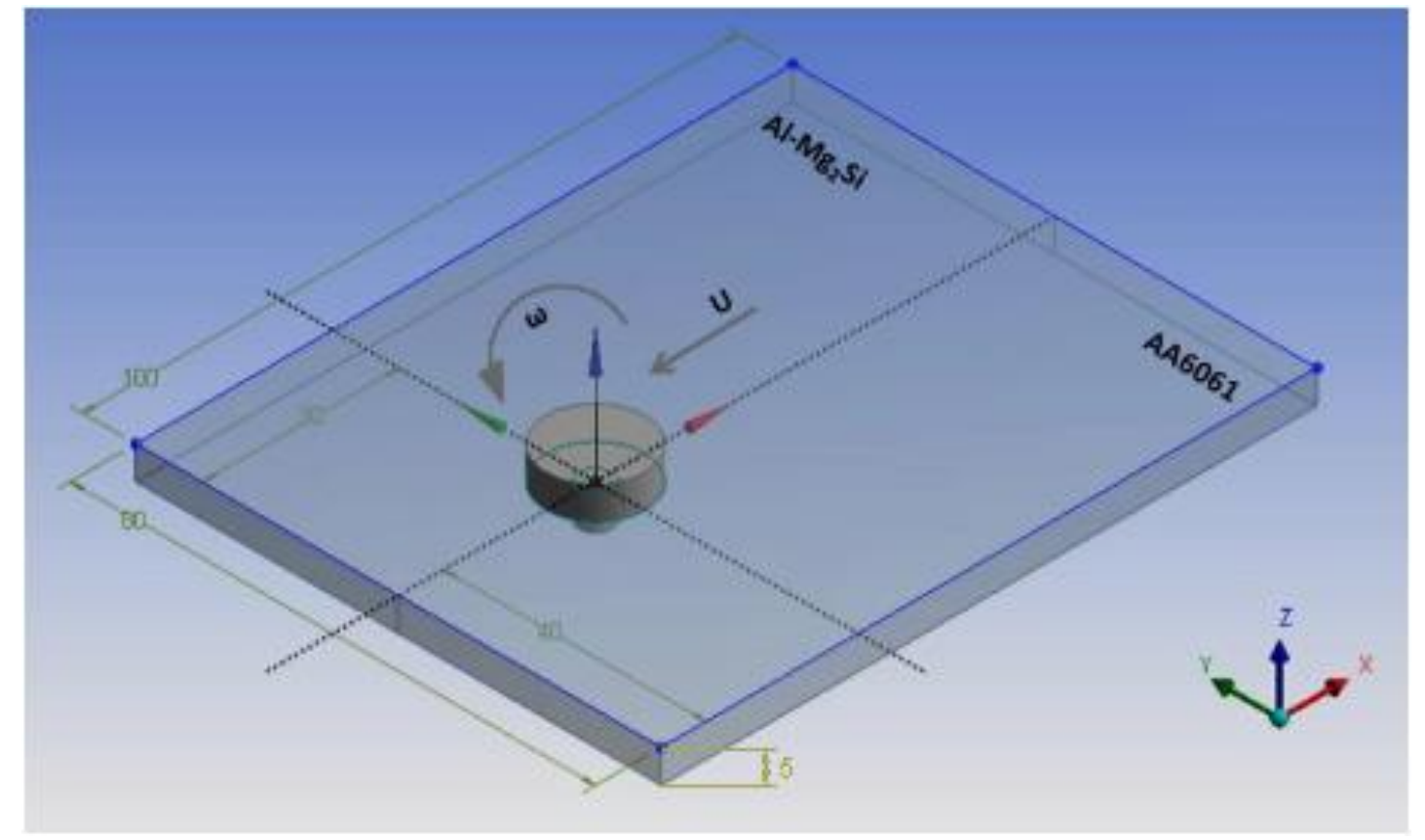

Fig. 1 Geometrical model used in simulations. The dimensions are in $\mathbf{m m}$.

The computational domain was divided into about 440000 non-uniform tetrahedrons. As shown in Figure 2, much smaller meshes are used in the workpieces below the tool for maximum resolution of variables due to the high variation in the temperature gradient and the heat generation concentration.

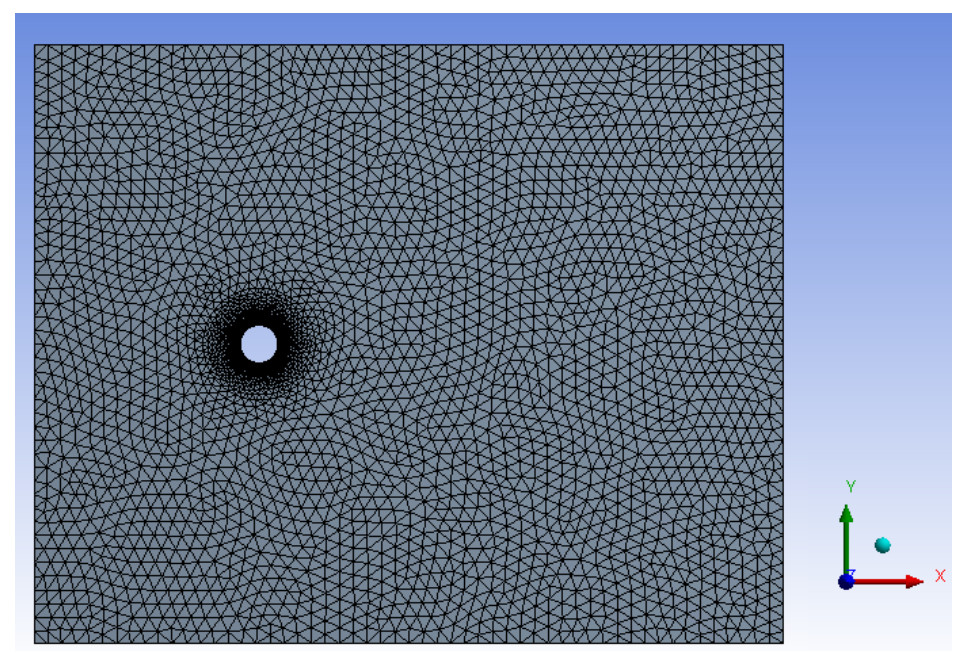

Fig. 2 Top view of non-uniform grid system. 
As presented in Figure 1, $\mathrm{Al}-\mathrm{Mg}_{2} \mathrm{Si}$ metal matrix composite is placed at the AS, and AA6061 aluminum alloy is considered at the RS. The material flows along the positive $\mathrm{X}$-direction from the surface on the left-hand side (inlet) to the opposite side on the righthand side (outlet) with a speed equal to the welding velocity. The tool is fixed in space, but it rotates counter-clockwise.

In the condition mentioned above, the conservation equations of mass, momentum, and energy are established as follows [14, 28]:

$\frac{\partial u_{i}}{\partial x_{i}}=0$

$\rho \frac{\partial u_{i} u_{j}}{\partial x_{i}}=-\frac{\partial P}{\partial x_{j}}+\frac{\partial}{\partial x_{i}}\left(\mu \frac{\partial u_{j}}{\partial x_{i}}+\mu \frac{\partial x_{i}}{\partial x_{j}}\right)-\rho V \frac{\partial u_{j}}{\partial x_{j}}$

$\rho C_{P} \frac{\partial\left(u_{i} T\right)}{\partial x_{i}}=-\rho C_{P} V \frac{\partial T}{\partial x_{i}}+\frac{\partial}{\partial x_{i}}\left(k \frac{\partial T}{\partial x_{i}}\right)+S_{\theta}$

where $u_{i}$ is the velocity in the $i$ direction, $x_{i}$ is the distance in the $\mathrm{i}=1,2$, and 3 directions, $\rho$ is the density, $\mathrm{V}$ is the welding speed in the negative $\mathrm{x}$-direction, $\mathrm{P}$ is the pressure, $\mathrm{k}$ is the thermal conductivity, $\mathrm{C}_{\mathrm{p}}$ is the specific heat, $\mathrm{T}$ is the temperature, and $\mathrm{S}_{\ominus}$ is the volumetric heat generation, which explained as Equation 4 [29].

$S_{\theta}=\beta \sigma \dot{\varepsilon}$

where $\beta$ defines as a proportion of heat generated by mechanical deformation and is in the range of 0.6 to 0.8 [30], $\dot{\varepsilon}$ is the strain rate, and $\sigma$ is the flow stress. The equations are independent on the time and the simulations were conducted in the steady-state condition.

The heat at the shoulder interface and the workpiece are given by the heat flux, $\mathrm{q}_{\mathrm{s}}$, in Equation 5.

$q_{s}=(\omega r-V \sin \theta)\left[\delta \tau+(1-\delta) \mu P_{T}\right]$

which includes the frictional heat and the heat produced by plastic deformation. In this equation, $\omega$ is the rotational speed, $\delta$ is the slip coefficient, $\mu$ is the friction coefficient, $\tau$ is the shear yield stress, and $\mathrm{P}_{\mathrm{T}}$ is the normal pressure which determined as $12.7 \mathrm{MPa}$, 
according to the reference [15]. The shear yield stress in Equation 5 described by Equation 6, where $\sigma_{\text {flow }}$ is the temperature-dependent flow stress of AA6061 aluminium alloy and $\mathrm{Al}-\mathrm{Mg}_{2} \mathrm{Si}$ composite $[29,30]$.

$\tau=\frac{\sigma_{\text {flow }}}{\sqrt{3}}$

The heat output at the normal interface of the workpieces and the pin is obtained by Equation 7 [26].

$q_{p}=\tau(\omega r-V \sin \theta)$

The heat is lost by convection on the side and the top planes of the workpieces with a heat transfer coefficient of $15 \mathrm{w} / \mathrm{m}^{2} \mathrm{~K}$. Also, the effect of the anvil on the workpieces is defined by a heat transfer coefficient of $1000 \mathrm{w} / \mathrm{m}^{2} \mathrm{~K}[24,31]$.

The relative velocity at the interface of the workpieces and the shoulder are written by Equations 8 and 9. Also, the relative velocity at the interface of the workpieces and the pin periphery is described by Equations 10, 11 and 12 [32].

$u_{s}=\omega r \sin \theta-V$

$v_{s}=\omega r \cos \theta$

$u_{p}=\omega R_{p} \sin \theta-V$

$v_{p}=\omega R_{p} \cos \theta$

$w_{p}=\left(\frac{\omega}{2 \pi}\right) R_{p}$

In the above equations, $\mathrm{u}_{\mathrm{s}}$, and $\mathrm{v}_{\mathrm{s}}$ are the shoulder relative velocities at the $\mathrm{x}$ and $\mathrm{y}$ directions, and $\mathrm{u}_{\mathrm{p}}, \mathrm{v}_{\mathrm{p}}$ and $\mathrm{w}_{\mathrm{p}}$ are the pin relative velocities at the $\mathrm{x}, \mathrm{y}$ and $\mathrm{z}$ directions, respectively, $\Theta$ is the angle between the welding direction and the vector from the desired point, $R_{\mathrm{p}}$ is the pin's radius, and $\mathrm{R}_{\mathrm{s}}$ is the shoulder's radius, and the $r$ is the radial distance between $\mathrm{R}_{\mathrm{p}}$ and $\mathrm{R}_{\mathrm{s}}\left(R_{p} \leq r \leq R_{s}\right)$ [33,34]. At all the other surfaces of the geometrical model, the initial velocities are set to be zero. 
The material viscosity is an essential parameter in the simulation based on the CFD. In this model, the dynamic viscosity is used by Equation 13, which depends on the strain rate and the temperature. This equation proposed first by Sellars and Tegart [35] and improved by Sheppard and Wright [36].

$\eta=\frac{\sigma(T, \bar{\varepsilon})}{3 \bar{\varepsilon}}$

In Equation 13, $\sigma$ is the flow stress, $\mathrm{T}$ is the temperature, and $\overline{\dot{\varepsilon}}$ is the effective strain rate. The flow stress has been defined by the Zener-Hollomon equation as below [37]:

$\sigma(T, \overline{\dot{\varepsilon}})=\frac{1}{\alpha} \ln \left[\left(\frac{Z}{A}\right)^{\frac{1}{n}}+\left[1+\left(\frac{Z}{A}\right)^{\frac{2}{n}}\right]^{\frac{1}{2}}\right]$

where $\alpha, \mathrm{A}$ and $\mathrm{n}$ are the constants related to the type of material, and $\mathrm{Z}$ is the ZenerHollomon parameter written by Equation 15 [37].

$Z=\overline{\dot{\varepsilon}} \exp \left(\frac{Q}{R T}\right)$

In Equation 15, Q and $\mathrm{R}$ are the activation energy and gas constant, respectively. The constants used in the above equations and the material properties of $\mathrm{Al}-\mathrm{Mg}_{2} \mathrm{Si} \mathrm{MMC}$, AA6061 aluminum alloy and the H13 tool steel are presented in Table 1.

Table 1 Material properties and constants used in the present research [33, 37-40].

\begin{tabular}{ccccc}
\hline Property & Unit & $\begin{array}{c}\mathrm{Al}-\mathrm{Mg}_{2} \mathrm{Si} \\
\text { composite }\end{array}$ & $\begin{array}{c}\text { AA6061 } \\
\text { aluminum alloy }\end{array}$ & $\begin{array}{c}\text { H13 hot } \\
\text { work steel }\end{array}$ \\
\hline Thermal conductivity & $(\mathrm{W} / \mathrm{m} . \mathrm{K})$ & 200.1 & 167 & 36 \\
Specific heat & $(\mathrm{J} / \mathrm{kg} \cdot \mathrm{K})$ & 897.6 & 896 & 460 \\
Density & $\left(\mathrm{kg} / \mathrm{m}^{3}\right)$ & 2411.3 & 2700 & 7833 \\
$\mu$ & - & 0.52 & 0.4 & - \\
$\mathrm{n}$ & - & 5.66 & 3.55 & - \\
$\mathrm{Q}$ & $\left(\mathrm{kJ} / \mathrm{mol}^{3}\right)$ & 131 & 145 & - \\
$\mathrm{a}$ & $\left(\mathrm{MPa}^{-1}\right)$ & 0.045 & 0.045 & - \\
$\mathrm{A}$ & $\left(\mathrm{s}^{-1}\right)$ & $5.17 \times 10^{10}$ & $8.86 \times 10^{6}$ & - \\
\hline
\end{tabular}


The VOF method is helpful to simulate the flow pattern of immiscible fluids during metallurgical processes. During FSW, the high plastic deformation and strain due to the rotation of the tool lead the base materials to mix together in the stir zone. The materials to be joined do not interpenetrate each other and just stirred. Hence, the VOF method can be utilized to simulate the dissimilar FSW, which involves the incompatible fluid flows. The base materials involved in the joint are defined as immiscible fluids or phases. The volume fraction of each phase can be calculated by Equation 16 .

$\nabla .\left(\alpha_{2} \rho_{2} u_{i}\right)=0$

In Equation 16, $\alpha_{2}$ and $\rho_{2}$ are the volume fraction and the density of the second phase, respectively [24].

The equations used to simulate the process have been described by the user-defined functions (UDF) and have been implemented in the model. The semi-implicit method for pressure-linked equations (SIMPLE) algorithm, the second-order upwind scheme and the double-precision solver have been used to solve the model. The model has been run for the welding velocity of $0.002 \mathrm{~m} / \mathrm{s}$ and three rotational speeds of 720,920 and $1120 \mathrm{rpm}$ to investigate the heat generation and the temperature fields. These parameters have been selected based on the experimental tests and previous works [4, 36]. Also, the simulation outcomes have been evaluated with the results of experimental tests.

\section{Experimental procedure}

Al-15 wt. \% $\mathrm{Mg}_{2} \mathrm{Si}$ in-situ reinforced composite and AA6061 aluminum alloy samples were prepared with length, width and thickness of 100,80 , and $5 \mathrm{~mm}$, respectively. Table 2 shows the composition of the base materials. 
Table 2 Chemical composition of the materials to be joined (wt. \%).

\begin{tabular}{lccccccccc}
\hline Alloy & $\mathrm{Mg}$ & $\mathrm{Cr}$ & $\mathrm{Fe}$ & $\mathrm{Si}$ & $\mathrm{Cu}$ & $\mathrm{Mn}$ & $\mathrm{Ni}$ & $\mathrm{Zn}$ & $\mathrm{Al}$ \\
& & & & & & & & & \\
\hline $\mathrm{Al}-\mathrm{Mg}_{2} \mathrm{Si}$ & 9.8 & 0.01 & 0.16 & 5.7 & 0.01 & 0.01 & 0.01 & 0.01 & Base \\
$\mathrm{AA6061}$ & 0.869 & 0.213 & 0.423 & 0.572 & 0.216 & 0.054 & 0.006 & 0.037 & Base \\
& & & & & & & & & \\
\hline
\end{tabular}

The welding experiments were done by a tool made of $\mathrm{H} 13$ hot-work steel with a flat shoulder. The shoulder diameter was $15 \mathrm{~mm}$, and the pin diameter was $5 \mathrm{~mm}$. The Al$\mathrm{Mg}_{2} \mathrm{Si}$ composite and the AA6061 aluminum plates were placed on the AS and the RS, respectively. To measure the temperature during welding, holes with $2 \mathrm{~mm}$ diameter and a depth of $2 \mathrm{~mm}$ were drilled on the top surface of both Al-alloy and composite plates. The distance of the holes from the weld seam line was $40 \mathrm{~mm}$ (and the holes are in the middle of two workpieces. The tip of flexible $\mathrm{K}$ type thermocouples was located in these holes. The arrangements of the workpieces and thermocouples, as well as the 2D sketch of the welding tool, are presented in Figure 3. 


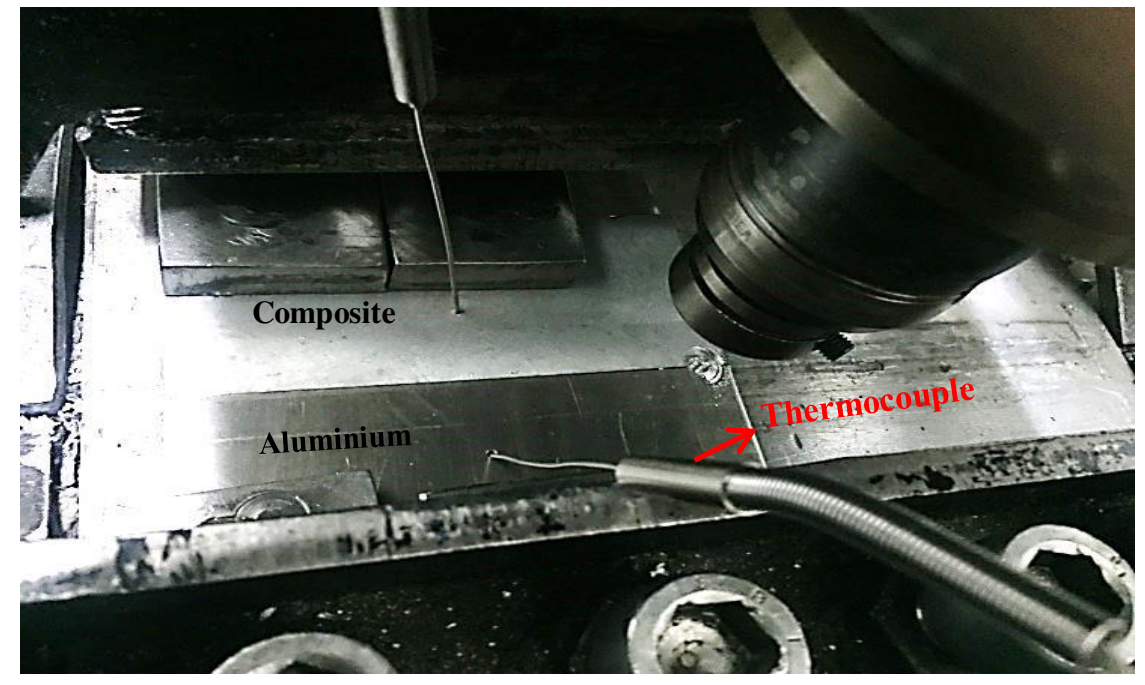

(a)

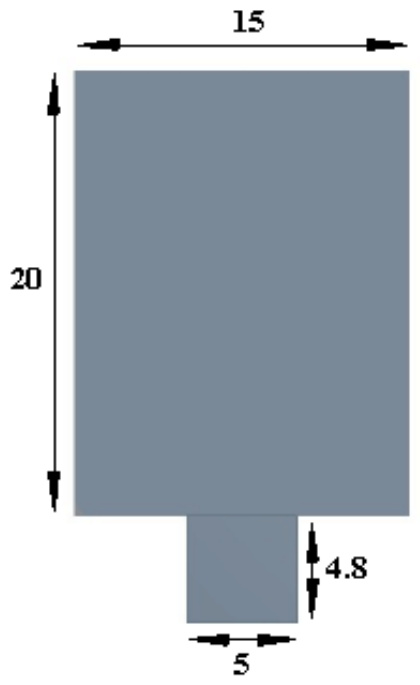

(b)

Fig. 3 a) Arrangement of workpieces and the thermocouples and b) two-dimensional sketch of tool used in the experiments and its size in $\mathrm{mm}$.

The thermocouples were connected to the data logger, and ten temperature data were recorded per second. The welding was accomplished under conditions similar to those used at the simulation. 


\section{Results and discussion}

In Figure 4, the 3D temperature contour at the workpiece and tool are shown. This contour is obtained for the welding speed of $0.002 \mathrm{~m} / \mathrm{s}$ and the rotational speed of 720 $\mathrm{rpm}$. The contours on the AS and the RS show the temperature changes of the $\mathrm{Al}-\mathrm{Mg}_{2} \mathrm{Si}$ composite and AA6061 aluminum alloy, respectively. The material in front of the tool is heating; however, the material at the back of the tool, which has already exposed to the peak temperature, is cooling. Besides, the temperature contours are extended behind the tool and condensed in front of it. Therefore, the material experiences a heating rate higher than the cooling rate [32].

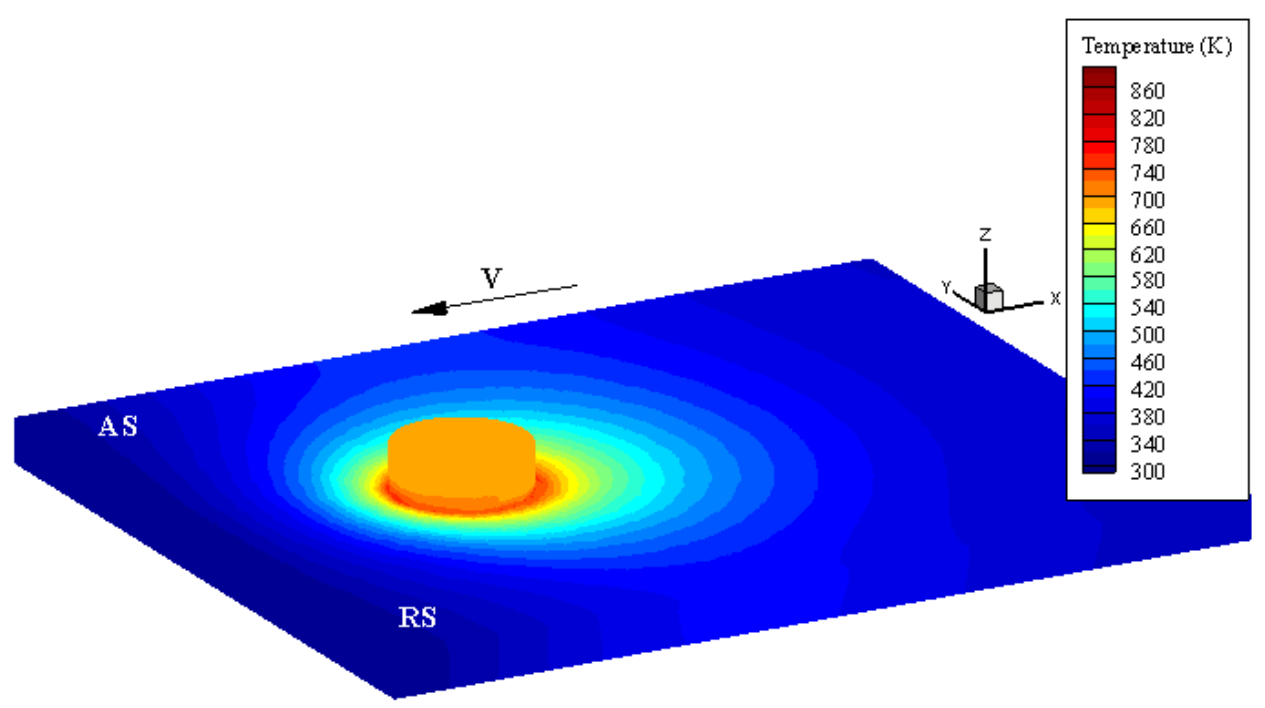

Fig. 4 Three-dimensional, steady-state contours of temperature distribution in the workpieces and tool.

The welding speed is $0.002 \mathrm{~m} / \mathrm{s}$, and rotational speed is $720 \mathrm{rpm}$ the.

The temperature distribution contour on the top surface of the workpiece is shown in Figure 5 for the rotational speed of $720 \mathrm{rpm}$. It is evident that the contours on the AS experience a higher expansion, but the Al-based alloy on the RS holds the heat more, which can be explained based on the higher thermal conductivity of $\mathrm{Al}-\mathrm{Mg}_{2} \mathrm{Si}$ composite.

The temperature fields at the cross-section of the samples for rotational speeds of 720 , 920 and 1120 rpm are shown in Figure 6. The temperature distribution in the cross- 
sections of all samples is asymmetric, which originates from the different material velocities on the AS and the RS. On the AS, the welding speed and the rotational speed are in the same direction, while they are in the opposite direction on the RS. Because of this difference, the relative velocities on the AS are higher than those on the RS, leading to higher shear rates and peak temperatures on the AS. The presence of a higher peak temperature on the AS during similar FSW confirms this issue [15], [26]. Also, the difference in physical properties of the materials, such as thermal conductivity (Table 1), can be the other reason for the asymmetric temperature fields. The values of the peak temperatures on both sides of the workpiece (AS and RS) and the rates of heat generation at the pin and shoulder surfaces for rotational speeds of 720, 920, and 1120 rpm are listed in Table 3. These values show that about 70 per cent of frictional heat generates at the interface between the workpiece and the shoulder. The contact surface of the workpiece and the shoulder with an area of $628.3 \mathrm{~mm}^{2}$ is more significant than that of the pin and the workpiece with $157 \mathrm{~mm}^{2}$, resulting in more heat generation. However, the tool shoulder area is 80 per cent of the whole contact area of the workpiece and the tool. Hence, the tool shoulder as a heat source is expected to affect mainly the upper part of the workpiece adjacent to the contact surface [15]. This issue is consistent with the temperature contours at the surface of the workpiece on the AS (Figure 5). Besides, the temperature and the width of the temperature contour on the AS decrease from the top surface to the bottom surface of the workpiece at three rotational speeds (Figure 6). However, the peak temperature on the RS is lower than that on the AS, and it develops under the top surface of the workpiece. The difference between the location of the peak temperature on the AS and the RS is material flow. Despite the fact that the heat is generated at the shoulder contact surface on the RS, the material moving from the front of the tool to the RS have a lower temperature than the material moving from the behind the tool to the AS. This movement leads to a decrease in the temperature at the upper surface of the workpiece adjacent to the tool shoulder. 


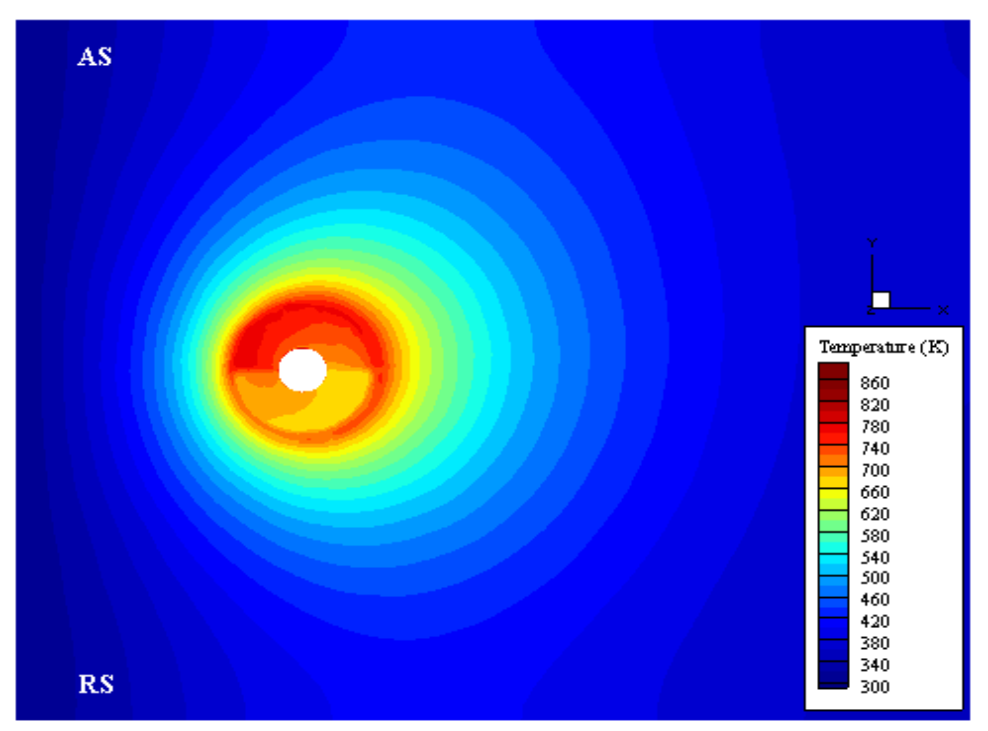

Fig. 5 Temperature contours on the top plane of the workpiece. The rotational speed is $720 \mathrm{rpm}$, and the welding speed is $0.002 \mathrm{~m} / \mathrm{s}$.

The comparison between the peak temperatures at different rotational speeds (Table 3) shows that the increase in the rotational speed leads to an increase ng the peak temperature. On the one hand, the peak temperature increases because the relative velocities between the tool and the workpiece increase at the higher rotational speeds. Hence, more plastic deformation and more heat generation occur. On the other hand, the material properties, such as viscosity and material strength, decrease during welding, which results in less heat generated. Therefore, when the rotational speed increases from 720 to $1120 \mathrm{rpm}$, the temperature rises significantly. However, it should be noticed that the increase in peak temperature is not continuous, and the peak temperature in FSW remains about $90 \%$ of the base metal solidus temperature. Similar behaviour was reported in the literature [14, 26, 42]. 

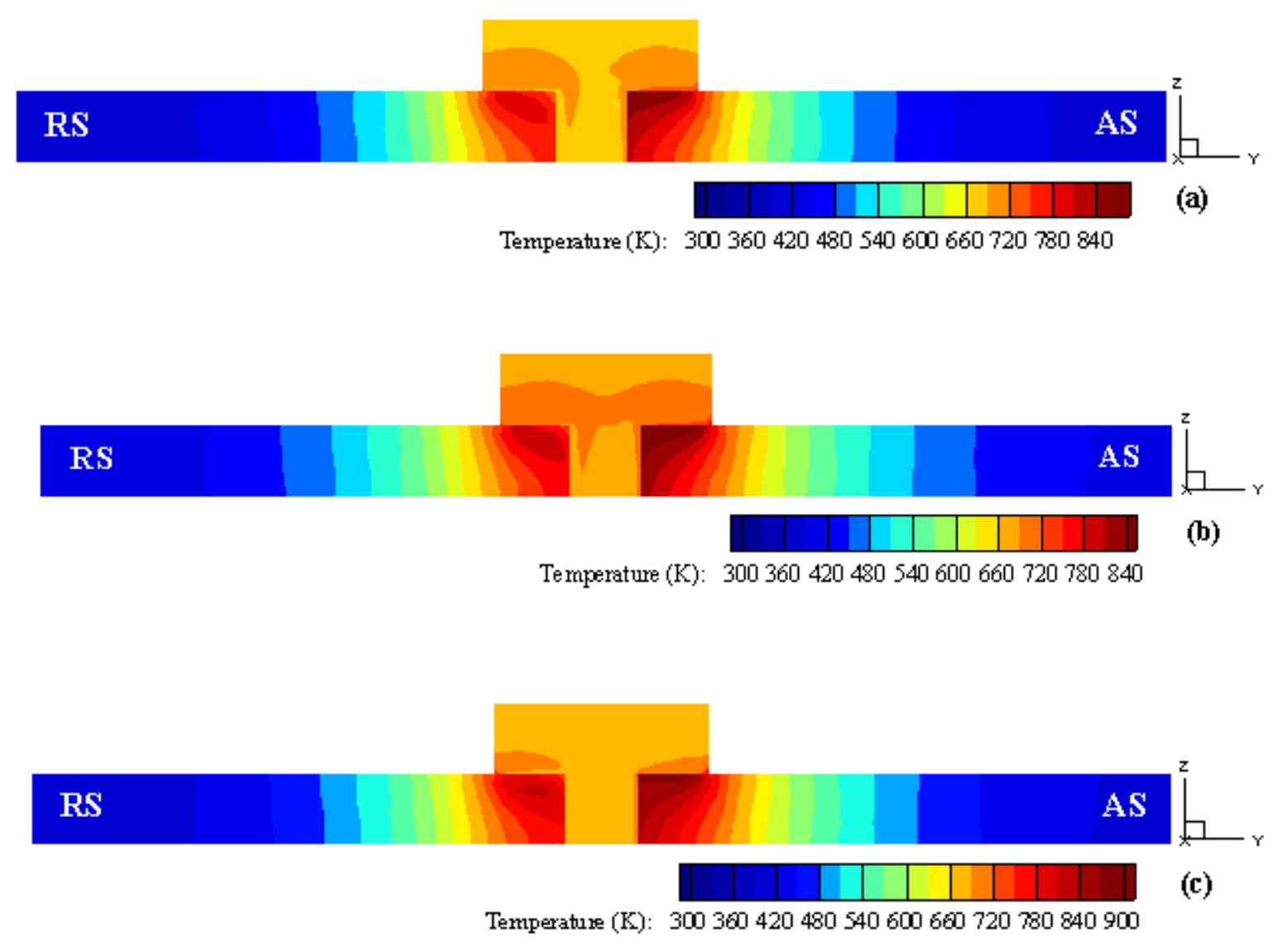

Fig. 6 Cross-sectional temperature contours at the $x=0$ for the rotational speeds of a) 720 , b) 920 , and c) $1120 \mathrm{rpm}$. The welding speed is $0.002 \mathrm{~m} / \mathrm{s}$.

Table 3 Comparison of the values of heat generation rate at the shoulder and pin and the peak temperatures at the RS and AS for three rotational speeds

\begin{tabular}{cccccc}
\hline $\begin{array}{c}\text { Rotational } \\
\text { speed (rpm) }\end{array}$ & $\begin{array}{c}\text { AS Peak } \\
\text { temperature } \\
(\mathrm{K})\end{array}$ & $\begin{array}{c}\text { RS peak } \\
\text { temperature } \\
(\mathrm{K})\end{array}$ & $\begin{array}{c}\text { Heat generation } \\
\text { rate at the } \\
\text { shoulder }(\mathrm{W})\end{array}$ & $\begin{array}{c}\text { Heat generation } \\
\text { rate at the pin } \\
(\mathrm{W})\end{array}$ & $\begin{array}{c}\text { Per cent of the generated } \\
\text { heat at the shoulder }\end{array}$ \\
\hline 720 & 864 & 765 & 809 & 354 & 70 \\
920 & 868 & 767 & 822 & 365 & 69 \\
1120 & 887 & 772 & 1116 & 483 & 70 \\
\hline
\end{tabular}

The variation in the temperature along the y-axis in the cross-section of the workpiece is illustrated in Figure 7. The difference between the peak temperature on the AS and on the RS is about $115 \mathrm{~K}$. The maximum temperature is located on the side of harder 
material, which is the AS in this joint [24]. This can result from the higher friction coefficient of the Al-Mg2Si composite compared to the Al-based alloy. The higher friction coefficient on the AS allows generating more heat in $\mathrm{Al}-\mathrm{Mg}_{2} \mathrm{Si}$ composite. Also, the tool rotational speed is in the direction of the welding speed on the AS and hence the shear rate and the generated heat increase, based on Equation 4.

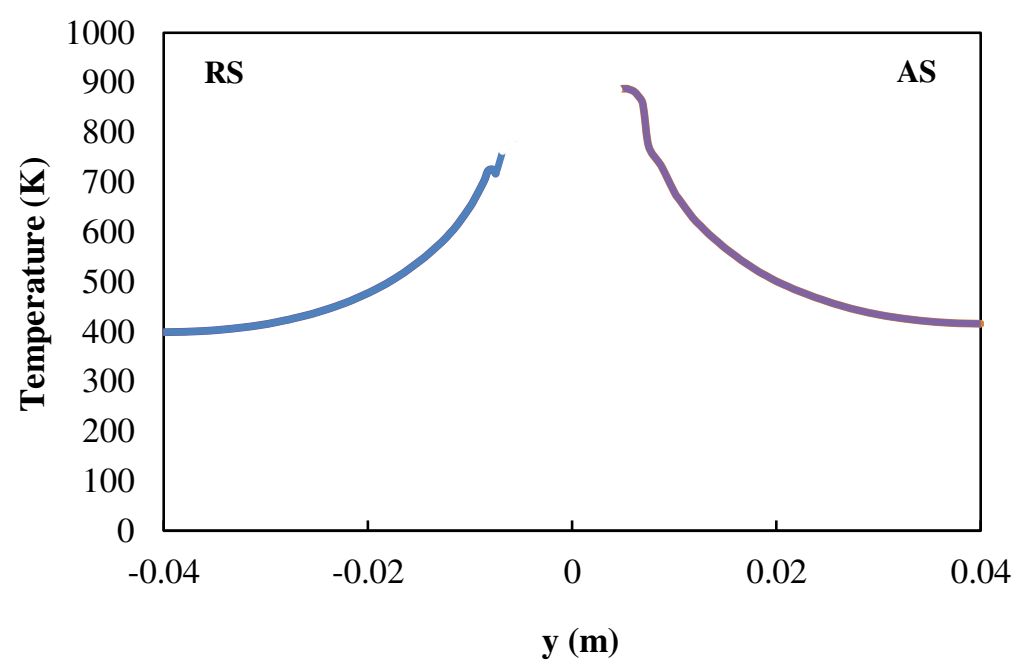

Fig. 7 Calculated values of temperature at $\mathrm{z}=\mathbf{0}$ and $\mathrm{x}=\mathbf{0}$. The rotational speed is $1120 \mathrm{rpm}$, and the welding speed is $0.002 \mathrm{~m} / \mathrm{s}$.

The calculated temperature-time graphs on the AS and RS for rotational speeds of 720, 920 and $1120 \mathrm{rpm}$ are compared in Figure 8. The thermal cycles, which the workpiece experienced during welding, is mostly similar for three rotational speeds. However, the peak temperature for the rotational speed of $1120 \mathrm{rpm}$ is higher because of the more stirring and the more deformation. The thermal cycle for the rotational speed of 920 rpm overlaps with the thermal cycle of $1120 \mathrm{rpm}$ on the AS, whereas on the RS the thermal cycle for the rotational speed of $720 \mathrm{rpm}$ is consistent with the thermal cycle of $1120 \mathrm{rpm}$.

In order to validate the temperature distribution obtained using the calculations, the thermal cycles in two monitoring locations of the workpiece were evaluated during FSW experimentally, and the results compared with the predicted results. The 
measuring points were located at the middle of the workpiece and $2 \mathrm{~mm}$ under the top surface on the AS and RS. The comparison of the experimental and predicted temperature profiles are shown in Figure 9. The results show a good agreement between the experimental and the predicted thermal cycles, despite a minor difference in peak temperatures. These differences probably emerge because of differences in the actual material properties and nominal properties used in the simulations. Also, the errors of measurements and the positioning of thermocouples can affect the experimental results. However, the model is credible for the prediction of the workpiece condition during and after FSW.
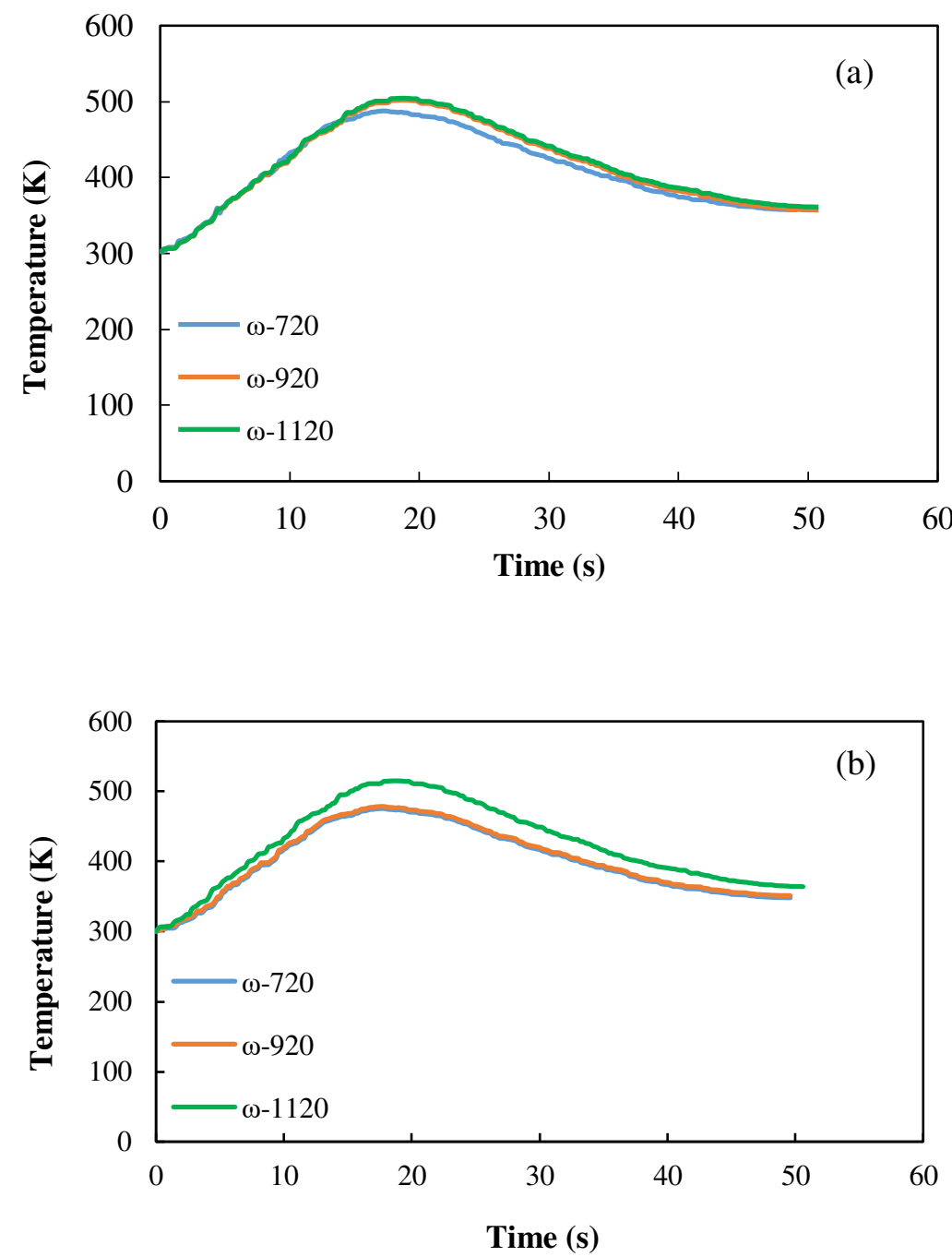

Fig. 8 Calculated temperature-time graphs at the middle of the workpiece $(\mathrm{z}=\mathbf{0 . 0 2 5})$ for rotational speeds on the a) AS and b) RS. The welding speed is $0.002 \mathrm{~m} / \mathrm{s}$. 

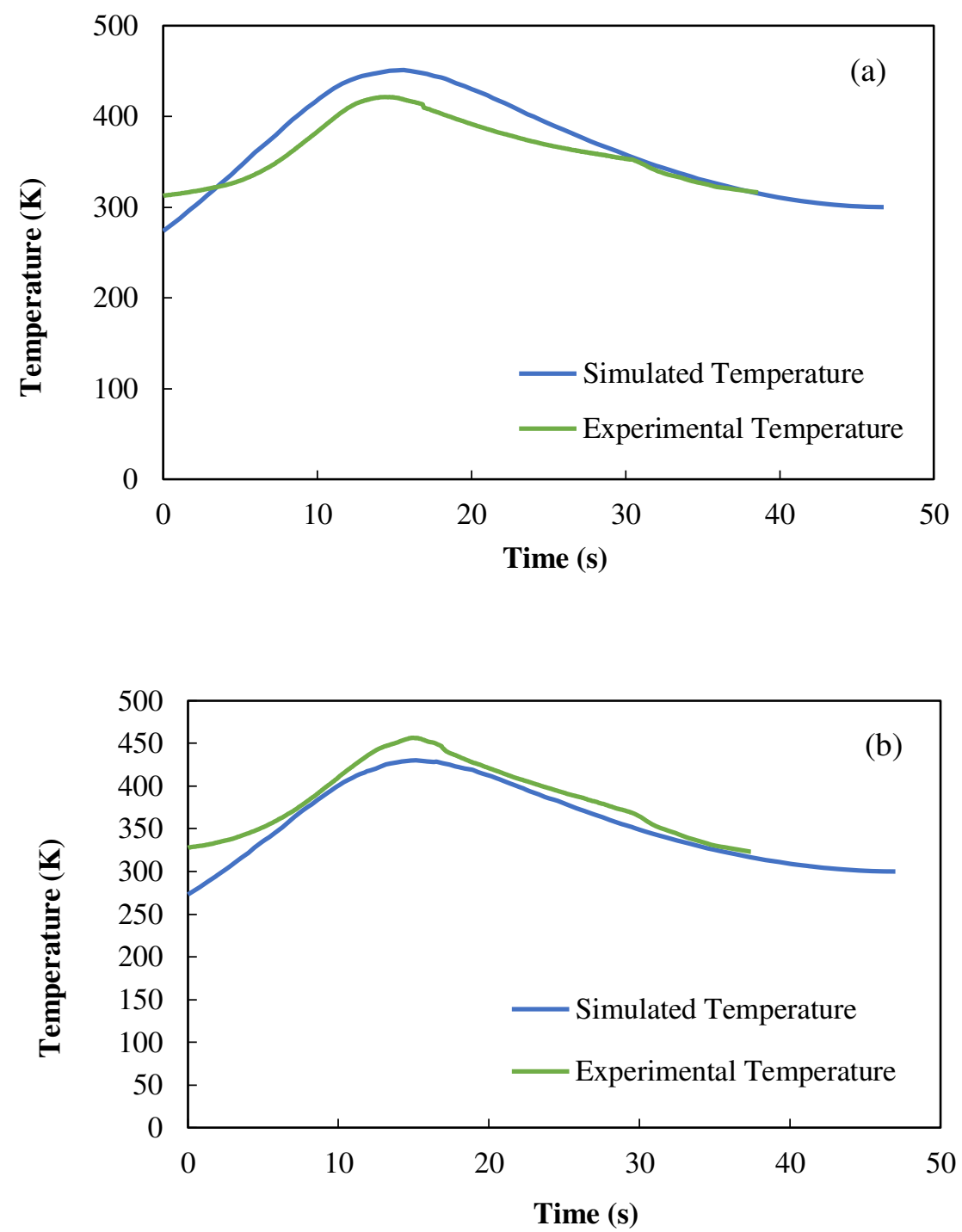

Fig. 9 The predicted and experimental thermal cycles comparison for the sample welded under the rotational speed of $1120 \mathrm{rpm}$ and the welding speed of $0.002 \mathrm{~m} / \mathrm{s} \mathrm{a}$ ) on the AS, b) on the RS

The thermal cycles at two monitoring locations in the stir zone $(\mathrm{z}=0, \mathrm{y}= \pm 5 \mathrm{~mm})$ and the heat-affected zone $(\mathrm{z}=0, \mathrm{y}= \pm 10 \mathrm{~mm})$ on the top plane at the AS and the RS for the sample welded under the rotational speed of $1120 \mathrm{rpm}$ and the welding speed of 0.002 $\mathrm{m} / \mathrm{s}$ are depicted in Figure 10. These cycles show the thermal histories in the given location of the workpiece during welding. They are calculated using the steady-state temperature fields (temperature-distance data) and the welding speed [41, 43]. 
As can be seen in Figure 10, the temperature increases with time rapidly and reaches a maximum value at the specified time. At this time, the tool is located around the monitoring location. The difference between the peak temperature in the SZ and the HAZ is about $150 \mathrm{~K}$ on both sides of the weld (AS and RS). The SZ that is located under the shoulder is affected by more heat and more heating rates because of the large plastic deformation and the more frictional heat produced in this zone. Following a rapid increase in temperature, a slighter decrease occurs because the tool as a heat source starts getting away from the monitoring location. For the HAZ, the same cycle is visible, but the heating and cooling rates are slower than the SZ because the distance of this zone from the heating source is more than the SZ. For instance, at the time below $10 \mathrm{~s}$, the heating rate on the AS is about 13.4 and $8.9 \mathrm{~K} / \mathrm{s}$ in the $\mathrm{SZ}$ and the $\mathrm{HAZ}$, respectively, and the heating rate in the similar range of time on the RS is about 17.6 and $12.4 \mathrm{~K} / \mathrm{s}$ in the SZ and the HAZ, respectively. Also, the cooling rate is about -10.6 and $-16.8 \mathrm{~K} / \mathrm{s}$ in the SZ and -6.4 and $-10.3 \mathrm{~K} / \mathrm{s}$ in the HAZ on the AS and RS, respectively. These data are summarised in Table 4. These results correspond to the temperature contours behind and in front of the tool in Figure 6. The compacted contours ahead of the tool are consistent with the heating rate, and the cooling rate agrees with the expanded contours behind the tool [15].

Table 4 Comparison between the values of heating and cooling rate in the SZ and HAZ on the AS and RS for the rotational speed of $1120 \mathrm{rpm}$ and the welding speed of $0.002 \mathrm{~m} / \mathrm{s}$

\begin{tabular}{ccccc}
\hline Side & \multicolumn{2}{c}{ AS } & \multicolumn{2}{c}{ RS } \\
\hline Zone & SZ & HAZ & SZ & HAZ \\
\hline Heating rate (K/s) & 13.4 & 8.9 & 17.6 & 12.4 \\
Cooling rate (K/s) & -10.6 & -6.4 & -16.8 & -10.3 \\
\hline
\end{tabular}



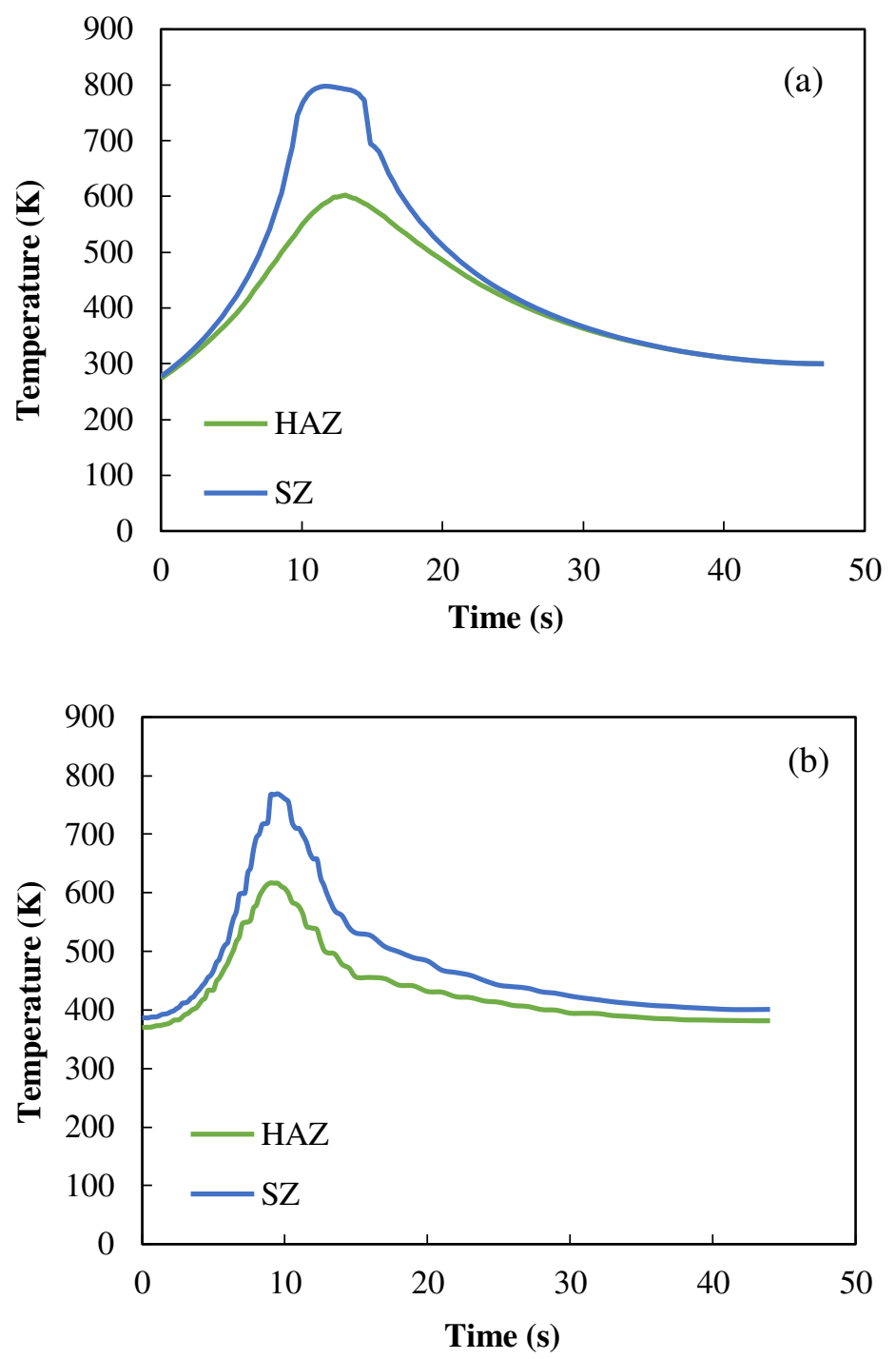

Fig. 10 Thermal cycles a) at the AS and b) at the RS, on the top surface of the workpiece ( $z=0)$. The welding speed is $0.002 \mathrm{~m} / \mathrm{s}$, and the rotational speed is $1120 \mathrm{rpm}$.

The velocity contour in the cross-section and near the pin periphery $(\mathrm{x}=0.0026)$ for the sample welded by the rotational speed is $1120 \mathrm{rpm}$ are presented in Figure 11. This figure shows that the velocity near the shoulder periphery is the maximum because of the maximum shoulder radius, and it is about $0.535 \mathrm{~m} / \mathrm{s}$. It is consistent with the relationship of the shoulder radius and the velocity in Equations 8 and 9. 


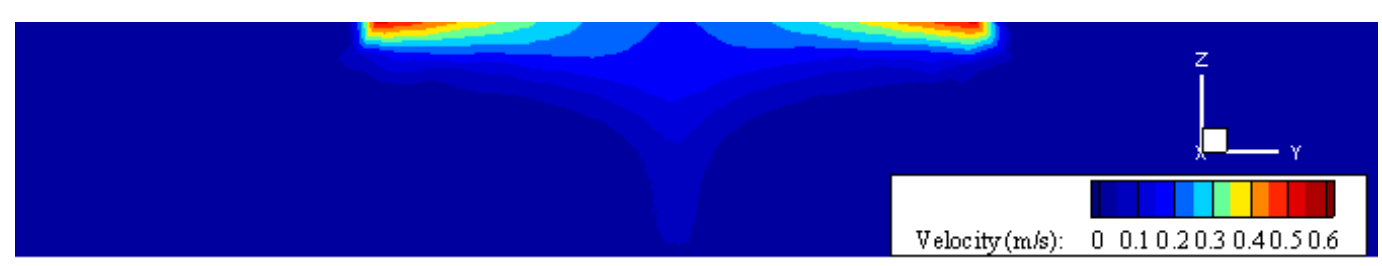

Fig. 11 The velocity contour in the workpiece cross-section $(x=0.0026)$. The welding speed is $0.002 \mathrm{~m} / \mathrm{s}$, and the rotational speed is $1120 \mathrm{rpm}$.

Figure 12 depicts the calculated volume fraction fields and the experimental crosssection macrostructures. On the calculated volume fraction results, the volume fraction of 0 and 1 (the area with blue and red color, respectively) can be assumed as $\mathrm{Al}-\mathrm{Mg}_{2} \mathrm{Si}$ composite and AA6061 aluminum alloy. Although the maximum temperature during FSW remains below the melting point of the base materials, the high plastic deformation and strain due to the tool rotation lead to heat generation and material softening. Thus, the materials undergo hard work and are mixed together in the stir zone. 

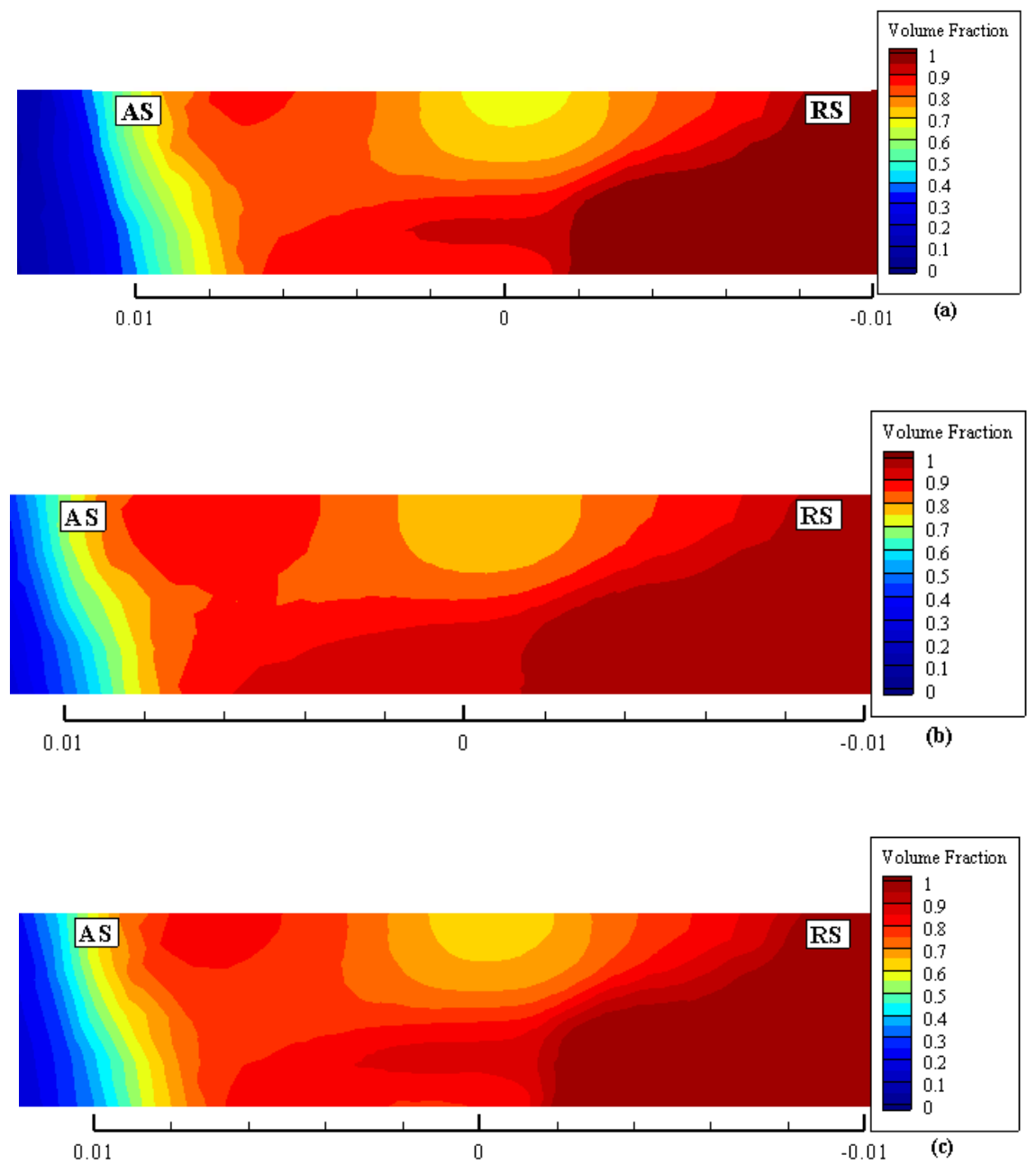

Fig. 12 Volume fraction contours of AA6061 aluminum alloy at the workpiece cross-section. The rotational speed is a) $720 \mathrm{rpm}$, b) $920 \mathrm{rpm}$, c) $1120 \mathrm{rpm}$. The welding speed is $0.002 \mathrm{~m} / \mathrm{s}$.

More material flow and metal combinations occur near the tool pin and shoulder surface, like SZ and TMAZ, because the temperature is high and material softening occurs. Also, the viscosity is low near the tool, as is evident in Figure 13. In this location, the strain rate is the highest. When the viscosity magnitude reaches $10^{6}$ and $10^{7}$ on the AS and RS, no more plastic deformation occurs, and no more heat generates. As illustrated in Figure 12, the size and the shape of the deformed area are predictable based on the volume fraction simulation results. 


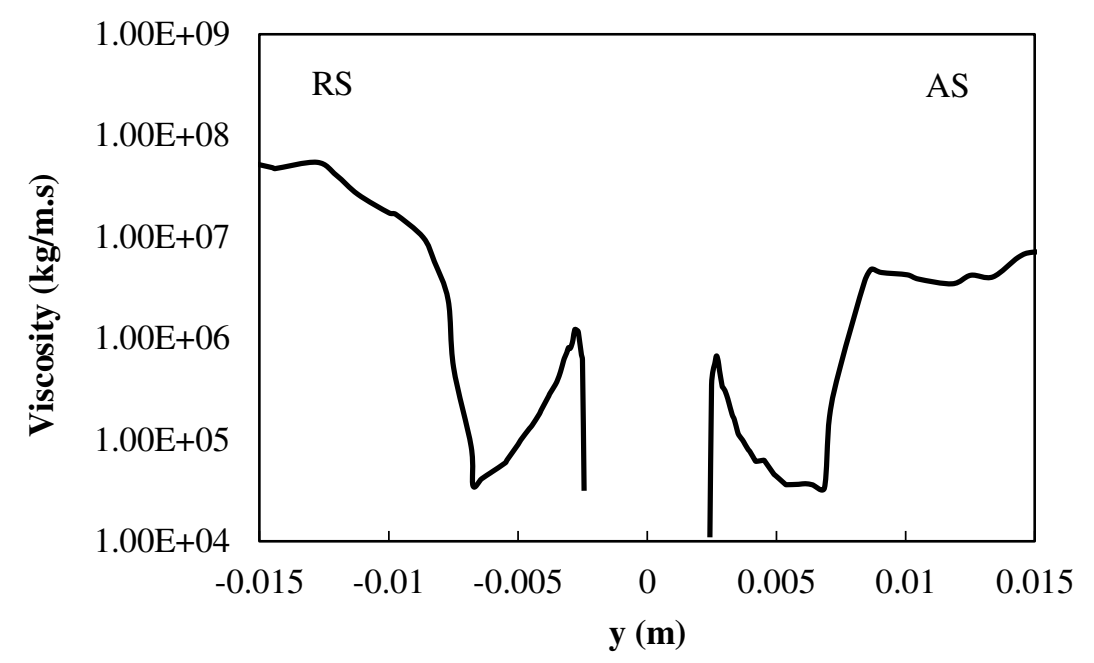

Fig. 13 The viscosity magnitude at the cross-section of the workpiece $(\mathrm{z}=\mathrm{x}=0)$ as a logarithm to base 10. The welding speed is $0.002 \mathrm{~m} / \mathrm{s}$, and the rotational speed is $1120 \mathrm{rpm}$.

\section{Conclusions}

The temperature distribution and heat generation during dissimilar friction stir welding (FSW) of $\mathrm{Al}-\mathrm{Mg}_{2} \mathrm{Si}$ metal matrix composite and AA6061 aluminum alloy were investigated using a 3-dimensional CFD model and FLUENT software. The calculated and the experimental thermal cycles were in good agreement. The temperature distribution in the cross-sections of all samples is asymmetric, which originates from the different material velocities on the retreating side (RS) and the advancing side (AS). The maximum temperature is generated in the harder material, which is on the AS of the joint, and the difference in the peak temperature on the RS and the AS is about 115 $\mathrm{K}$. The peak temperature on the RS develops below the top surface. In contrast, the peak temperature on the AS develops on the surface of the workpiece. About 70 per cent of the heat generates at the contact surface of the workpiece and the shoulder. The temperature contours are expanded on the AS because of the higher thermal conductivity of Al- $\mathrm{Mg}_{2} \mathrm{Si}$ composite. With increasing the rotational speed from 720 to $1120 \mathrm{rpm}$, the temperature increases significantly and the peak temperature in FSW remains about $90 \%$ of the base metal solidus temperature. 


\section{Declarations}

\section{Funding}

The authors did not receive support from any organization for the submitted work.

\section{Conflicts of interest/Competing interests}

The authors have no relevant financial or non-financial interests to disclose.

\section{Availability of data and material}

The data and material that support the findings of this study are available on request.

\section{Code availability}

Not applicable.

\section{References}

[1] P. Prakash, S. Kumar Jha, and S. P. Lal, "A study of process parameters of friction stir welded AA 6061 aluminum alloy," International Journal of Innovative Research in Science, Engineering and Technology, vol. 2, no. 6, pp. 2304-2309, 2013.

[2] S. A. David and Z. Feng, "Friction stir welding of advanced materials: challenges," 2004.

[3] K. S. Bang, K. J. Lee, H. S. Bang, and H. S. Bang, "Interfacial microstructure and mechanical properties of dissimilar friction stir welds between 6061-T6 aluminum and Ti-6\% Al-4\%V alloys," Materials Transactions, vol. 52, no. 5, pp. 974-978, 2011. 
[4] M. Sharifitabar and H. Nami, "Microstructures of dissimilar friction stir welded joints between 2024-T4 aluminum alloy and $\mathrm{Al} / \mathrm{Mg}_{2} \mathrm{Si}$ metal matrix cast composite," Composites Part B Engineering, vol. 42, no. 7, pp. 2004-2012, 2011.

[5] N. Nasiri, M. Emamy, A. Malekan, and M. H. Norouzi, "Microstructure and tensile properties of cast $\mathrm{Al}-15 \% \mathrm{Mg}_{2} \mathrm{Si}$ composite: Effects of phosphorous addition and heat treatment," Materials Science and Engineering: A, vol. 556, pp. 446-453, 2012.

[6] A. Jahangiri, M. H. Idris, and S. Farahany, "Investigation on tungsten inert gas welding of in situ Al-15 and $20 \mathrm{Mg}_{2} \mathrm{Si}$ composites with an Al-Si filler," Journal of composite materials, vol. 47, no. 10, pp. 1283-1291, 2012.

[7] S. Dalkilic and G. Biallas, "Fsw Joints of an aluminium base metal matrix composite and a monolithic aluminium alloy," Proc. $6^{\text {th }}$ International Symposium on Friction Stir Welding, pp. 10-13, 2006.

[8] P. Cavaliere, "Friction stir welding of Al alloys: Analysis of processing parameters affecting mechanical behavior," Procedia CIRP, vol. 11, pp. 139-144, 2013.

[9] A. Farzadi, M. Bahmani, and D. F. Haghshenas, "Optimization of operational parameters in friction stir welding of AA7075-T6 aluminum alloy using response surface method," Arabian Journal for Science and Engineering, vol. 42, no. 11, pp. 4905-4916, 2017.

[10] D. Kim, H. Badarinarayan, I. Ryu, J. H. Kim, Ch. Kim, K. Okamoto, R. H. Wagoner, K. Chung, "Numerical simulation of friction stir welding process," International Journal of Material Forming, vol. 2, no. 1, pp. 383-386, 2009.

[11] A. K. Lakshminarayanan and V. Balasubramanian, "Process parameters optimization for friction stir welding of RDE-40 aluminium alloy using Taguchi technique," Transactions of Nonferrous Metals Society of China, vol. 18, no. 3, pp. 548-554, 2008. 
[12] W. Tang, X. Guo, J. C. McClure, L. E. Murr, and A. Nunes, "Heat input and temperature distribution in friction stir welding," Journal of Materials Processing and Manufacturing Science, vol. 7, no. 2, pp. 163-172, 1998.

[13] P. Surendrababu, A. G. Krishna, and C. S. Rao, "Material flow behaviour in friction stir welding process-A critical review on process parameters and modeling methodologies," International Journal of Emerging Technology and Advanced Engineering, vol. 3, no. 6, pp. 219-225, 2013.

[14] A. P. Reynolds, W. Tang, Z. Khandkar, J. A. Khan, and K. Lindner, "Relationships between weld parameters, hardness distribution and temperature history in alloy 7050 friction stir welds," Science and Technology of Welding and Joining, vol. 10, no. 2, pp. 190-199, 2005.

[15] R. Nandan, G. G. Roy, and T. Debroy, "Numerical simulation of threedimensional heat transfer and plastic flow during friction stir welding," Metallurgical and Materials Transactions A, vol. 37, no.4, pp. 1247-1259, 2005.

[16] G. Chen, S. Zhang, Y. Zhu, C. Yang, and Q. Shi, "Thermo-mechanical analysis of friction stir welding: A review on recent advances," Acta Metallurgical Sinica (English Letters), vol. 33, no. 1, pp. 3-12, 2020.

[17] G. Chen, Z. Feng, Y. Zhu, and Q. Shi, "An alternative frictional boundary condition for computational fluid dynamics simulation of friction stir welding," Journal of Materials Engineering and Performance, vol. 25, no. 9, pp. 40164023, 2016.

[18] G. Chen H. Li, S. Zhang, Q. Dai, X. Wang, G. Zhang, and Q. Shi, "Effects of pin thread on the in-process material flow behavior during friction stir welding: A computational fluid dynamics study," International Journal of Machine Tools and Manufacture, vol. 124, pp. 12-21, 2018.

[19] M. Zhai, C. S. Wu, and H. Su, "Influence of tool tilt angle on heat transfer and material flow in friction stir welding," Journal of Manufacturing Processes, vol. 59, pp. 98-112, 2020. 
[20] C. L. Yang, C. S. Wu, and X. Q. Lv, "Numerical analysis of mass transfer and material mixing in friction stir welding of aluminum/magnesium alloys," Journal of Manufacturing Processes, vol. 32, pp. 380-394, 2018.

[21] A. Arora, A. De, and T. Debroy, "Toward optimum friction stir welding tool shoulder diameter," Scripta Materialia, vol. 64, no. 1, pp. 9-12, 2011.

[22] S. Zhang, Q. Shi, Q. Liu, R. Xie, G. Zhang, and G. Chen, "Effects of tool tilt angle on the in-process heat transfer and mass transfer during friction stir welding," International Journal of Heat and Mass Transfer, vol. 125, pp. 32-42, 2018.

[23] G. Chen, G. Wang, Q. Shi, Y. Zhao, Y. Hao, and S. Zhang, "Three-dimensional thermal-mechanical analysis of retractable pin tool friction stir welding process," Journal of Manufacturing Processes, vol. 41, pp. 1-9, 2019.

[24] V. R. . Kishore, J. Arun, R. Padmanabhan, and V. Balasubramanian, "Parametric studies of dissimilar friction stir welding using computational fluid dynamics simulation," The International Journal of Advanced Manufacturing Technology, vol. 80, no. 1-4, pp. 91-98, 2015.

[25] S. Zhang, G. Chen, Q. Liu, H. Li, G. Zhang, G. Wang, Q. Shi, "Numerical analysis and analytical modeling of the spatial distribution of heat $\mathrm{fl}$ ux during friction stir welding," Journal of Manufacturing Processes, vol. 33, pp. 245-255, 2018.

[26] R. Padmanaban, V. R. Kishore, and V. Balusamy, "Numerical simulation of temperature distribution and material flow during friction stir welding of dissimilar aluminum alloys," Procedia Engineering, vol. 97, pp. 854-863, 2014.

[27] N. Gotawala and A. Shrivastava, "Analysis of material distribution in dissimilar friction stir welded joints of Al 1050 and copper," Journal of Manufacturing Processes, vol. 57, pp. 725-736, 2020.

[28] H. A. Derazkola, M. Elyasi, and M. Hosseinzadeh, "CFD modeling of friction stir 
welding of AA1100 aluminum alloy to A441 AISI steel butt joint," Journal of Advanced Materials and Processing, vol. 3, no. 3, pp. 47-59, 2015.

[29] G. Yoshikawa, F. Miyasaka, Y. Hirata, Y. Katayama, and T. Fuse, "Development of numerical simulation model for FSW employing particle method," Science and Technology of Welding and Joining, vol. 17, no. 4, pp. 255-263, 2012.

[30] R. Nandan, T. Debroy, and H. K. D. H. Bhadeshia, "Recent advances in frictionstir welding - Process, weldment structure and properties," Progress in Materials Science, vol. 53, no. 6, pp. 980-1023, 2008.

[31] G. E. Totten, D. S. MacKenzie, eds., "Handbook of Aluminum: Volume 2: Alloy Production and Materials Manufacturing," vol. 2, 2003.

[32] R. Nandan, G. G. Roy, T. J. Lienert, and T. Debroy, "Three-dimensional heat and material flow during friction stir welding of mild steel," Acta Materialia, vol. 55, no. 3, pp. 883-895, 2007.

[33] T. K. Bhattacharya, H. Das, S. S. Jana, and T. K. Pal, "Numerical and experimental investigation of thermal history, material flow and mechanical properties of friction stir welded aluminium alloy to DHP copper dissimilar joint," The International Journal of Advanced Manufacturing Technology, vol. 88, no. 1-4, pp. 847-861, 2017.

[34] A. P. Reynolds, M. Z. H. Khandkar, J. A. Khan, and A. P. Reynolds, "Prediction of temperature distribution and thermal history during friction stir welding : Input torque based model Prediction of temperature distribution and thermal history during friction stir welding : input torque based model," Science and Technology of Welding and Joining, vol. 8, no. 3, pp. 165-174, 2003.

[35] C. M. Sellars and W. J. M. Tegart, "Hot Workability," International Metallurgical Reviews, vol. 17, no. 1, pp. 1-24, 1972.

[36] T. Sheppard and D. S. Wright, "Determination of flow stress: Part 1 constitutive equation for aluminium alloys at elevated temperatures," Metals Technolog, vol. 
6, no. 1 , pp. $215-223,1979$.

[37] E. Sharghi and A. Farzadi, "Simulation of strain rate, material fl ow , and nugget shape during dissimilar friction stir welding of AA6061 aluminum alloy and AlMg 2 Si composite," Journal of Alloys and Compounds, vol. 748, pp. 953-960, 2018.

[38] C. Hamilton, S. Dymek, and A. Sommers, "A thermal model of friction stir welding in aluminum alloys," International Journal of Machine Tools and Manufacture, vol. 48, no. 10, pp. 1120-1130, 2008.

[39] J. Zhang, Z. Fan, Y. Wang, and B. Zhou, "Microstructure and mechanical properties of in situ Al - Mg 2 Si composites," Materials Science and Technology, vol. 16, no. 7-8, pp. 913-918, 2000.

[40] P. A. Colegrove and H. R. Shercliff, "3-Dimensional CFD modelling of flow round a threaded friction stir welding tool profile," Journal of Materials Processing Technology, vol. 169, no. 2, pp. 320-327, 2005.

[41] A. Farzadi, "Correlation between precipitate microstructure and mechanical properties in AA7075-T6 aluminum alloy friction stir welded joints," Materialwissenschaft und Werkstofftechnik, vol. 48, no. 2, pp. 151-162, 2017.

[42] P. A. Colegrove and H. R. Shercliff, "CFD modelling of friction stir welding of thick plate 7449 aluminium alloy," Science and Technology of Welding and Joining, vol. 11, no. 4, pp. 429-441, 2006.

[43] A. Farzadi, S. Serajzadeh, and A. H. Kokabi, "Prediction of solidification behaviour of weld pool through modelling of heat transfer and fluid flow during gas tungsten arc welding of commercial pure aluminium," Materials Science and Technology, vol. 24, no. 12, pp. 1427-1432, 2008. 


\section{Figures}

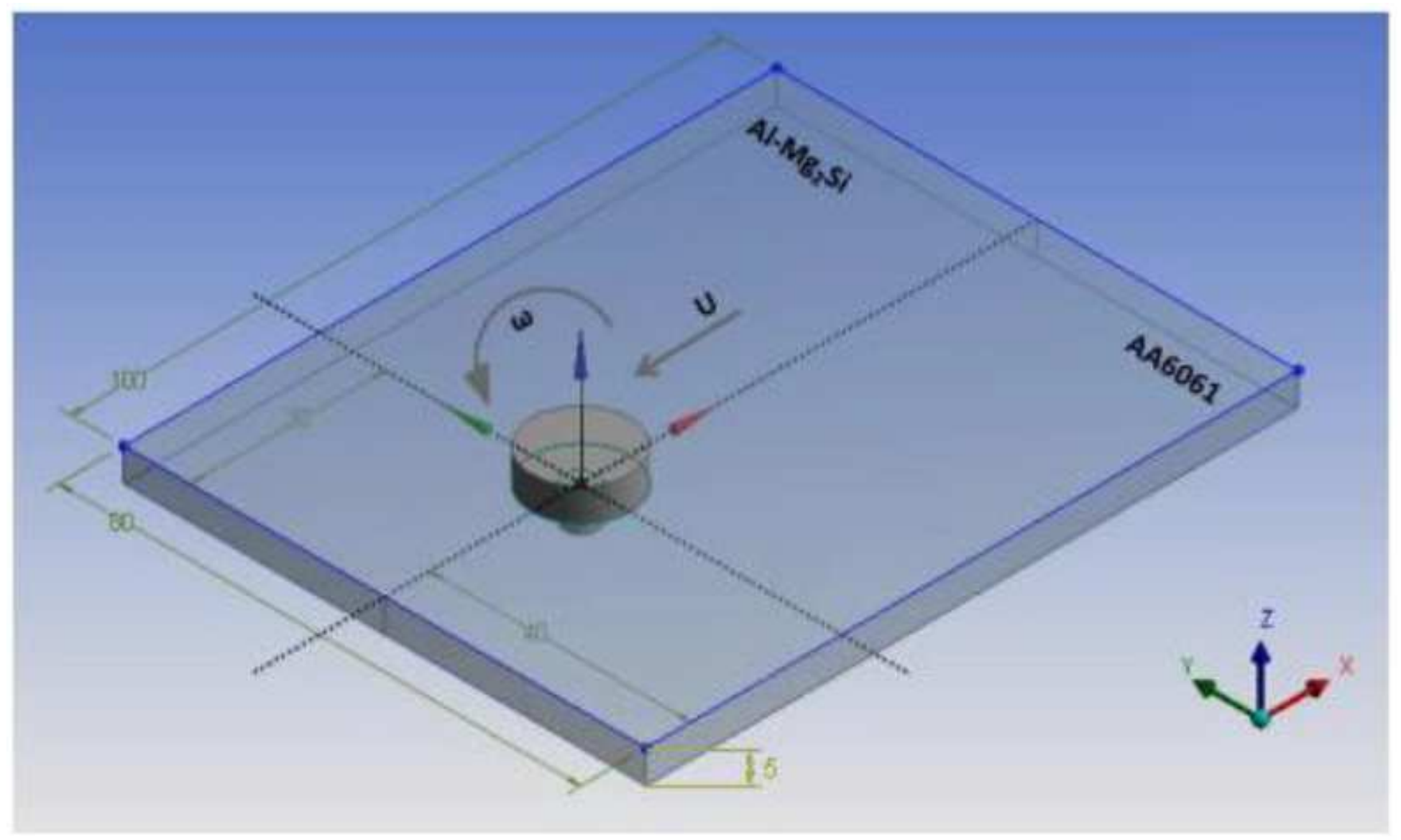

\section{Figure 1}

Geometrical model used in simulations. The dimensions are in $\mathrm{mm}$. 


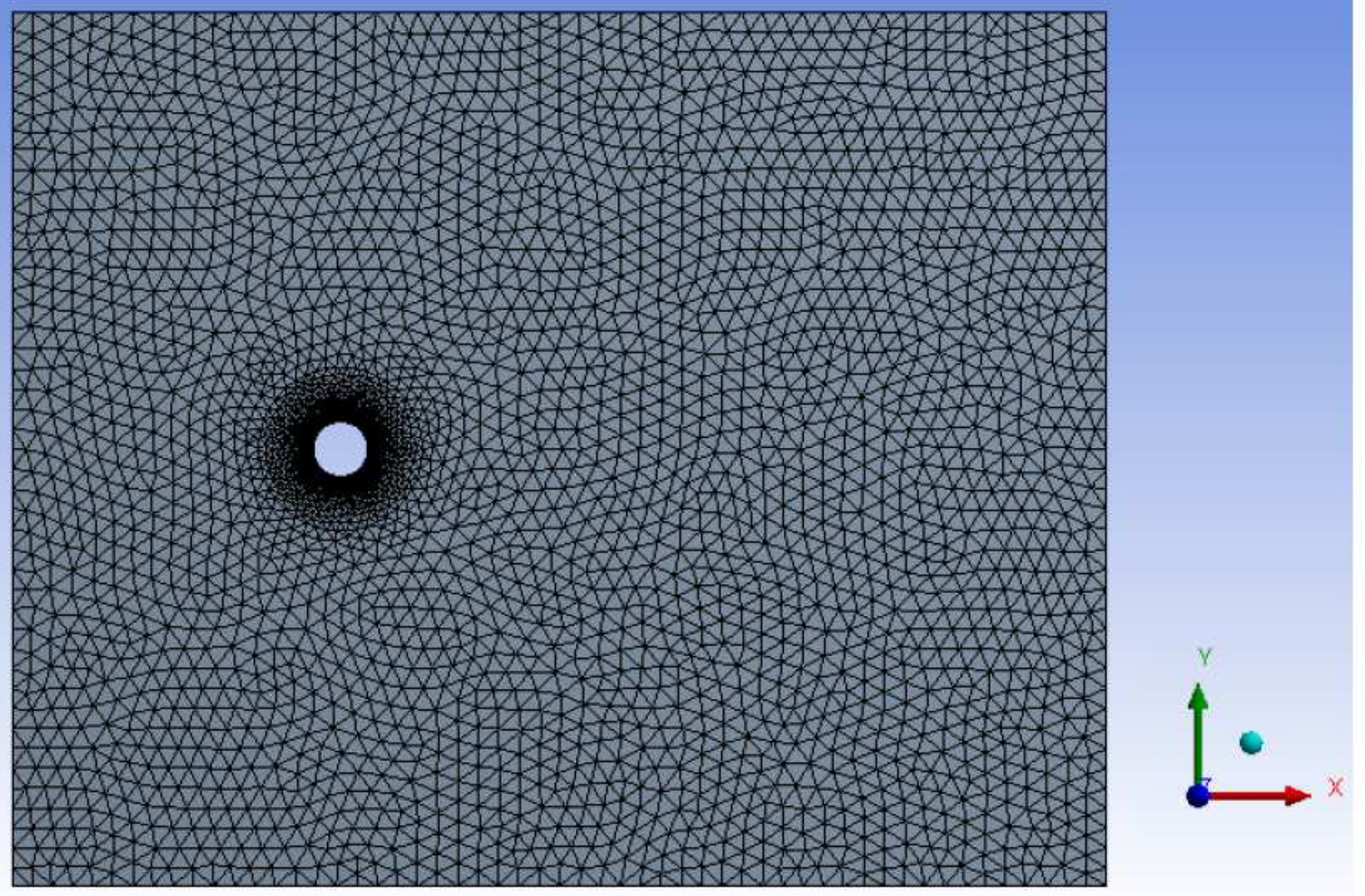

Figure 2

Top view of non-uniform grid system. 


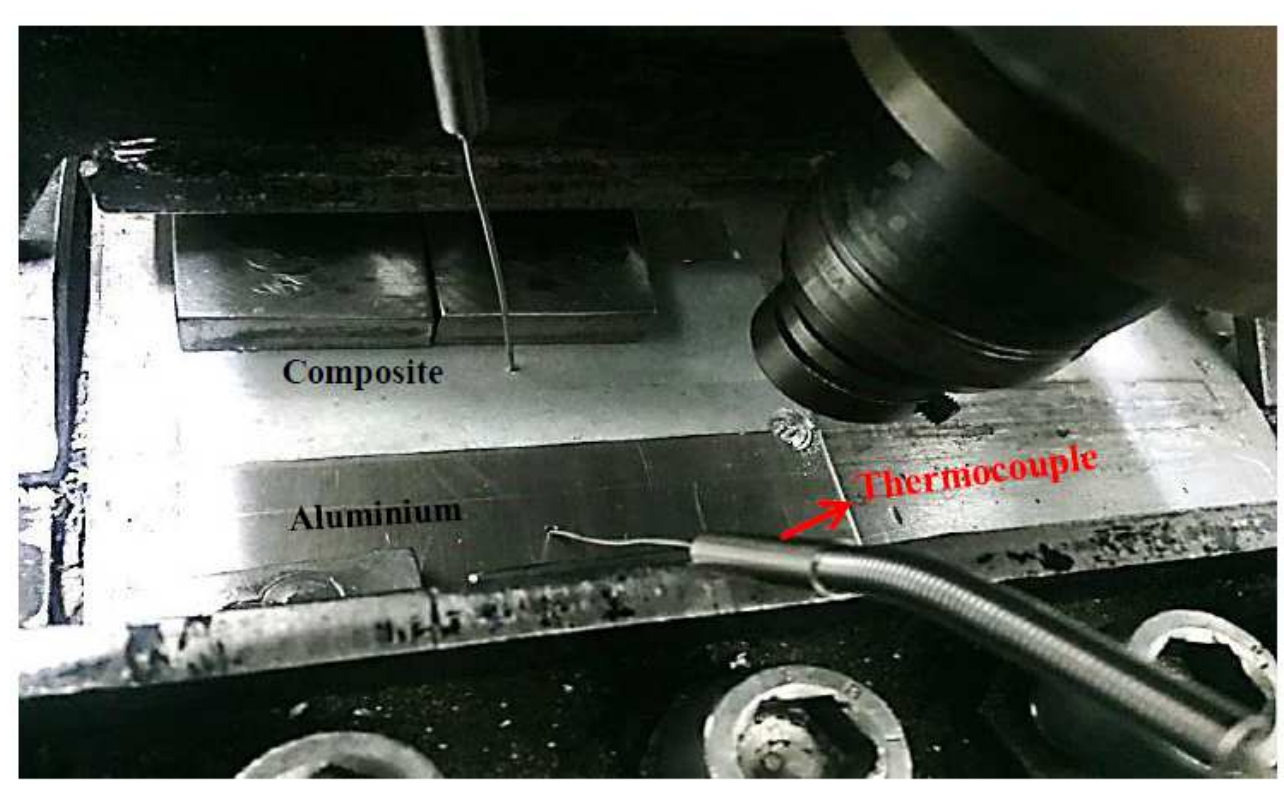

(a)

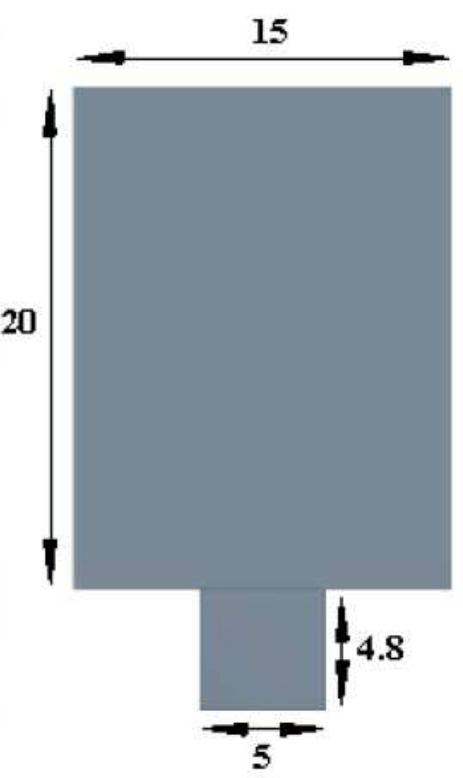

(b)

\section{Figure 3}

a) Arrangement of workpieces and the thermocouples and b) two-dimensional sketch of tool used in the experiments and its size in $\mathrm{mm}$.

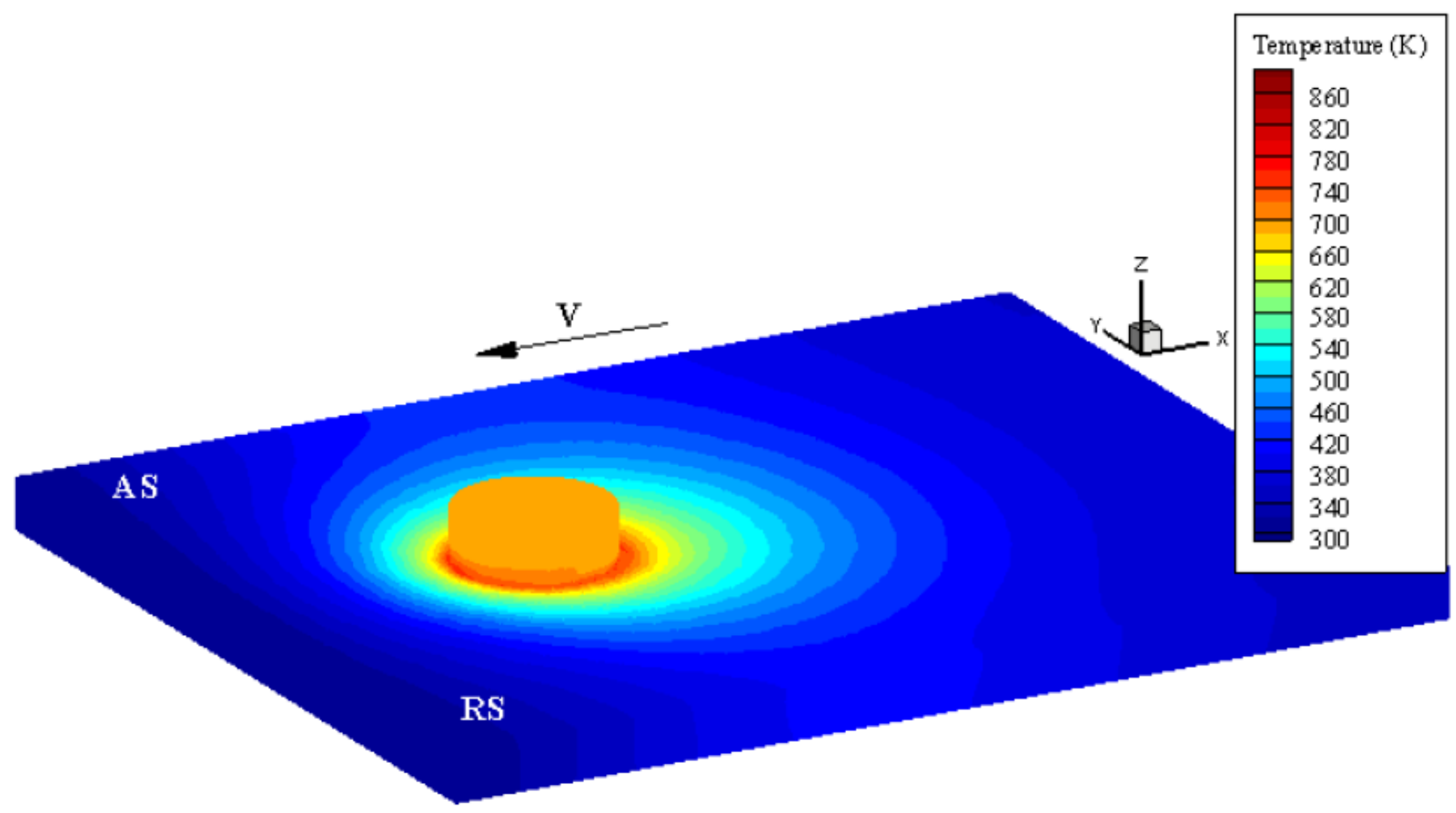

Figure 4 
Three-dimensional, steady-state contours of temperature distribution in the workpieces and tool. The welding speed is $0.002 \mathrm{~m} / \mathrm{s}$, and rotational speed is $720 \mathrm{rpm}$ the.

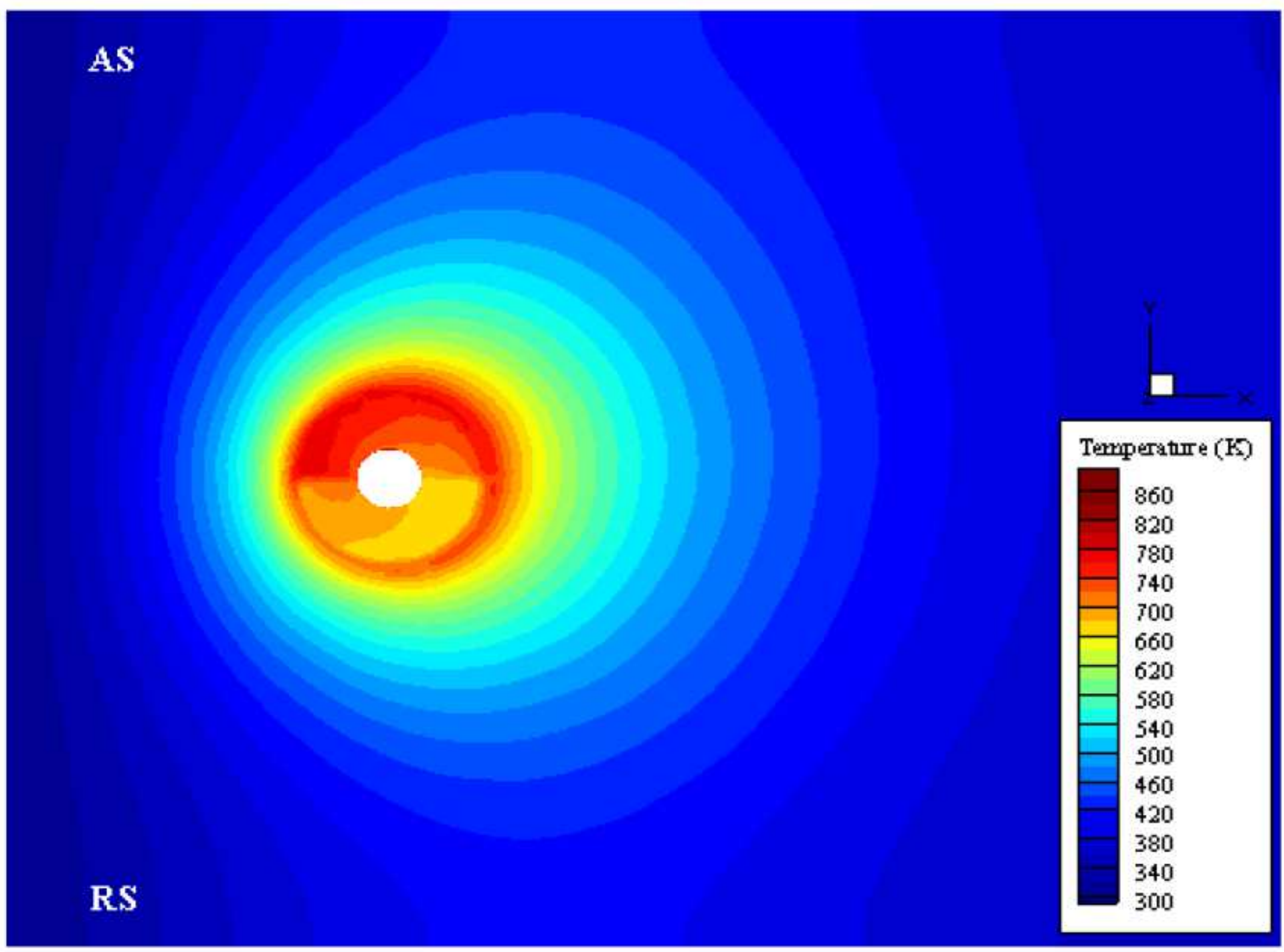

Figure 5

Temperature contours on the top plane of the workpiece. The rotational speed is $720 \mathrm{rpm}$, and the welding speed is $0.002 \mathrm{~m} / \mathrm{s}$. 

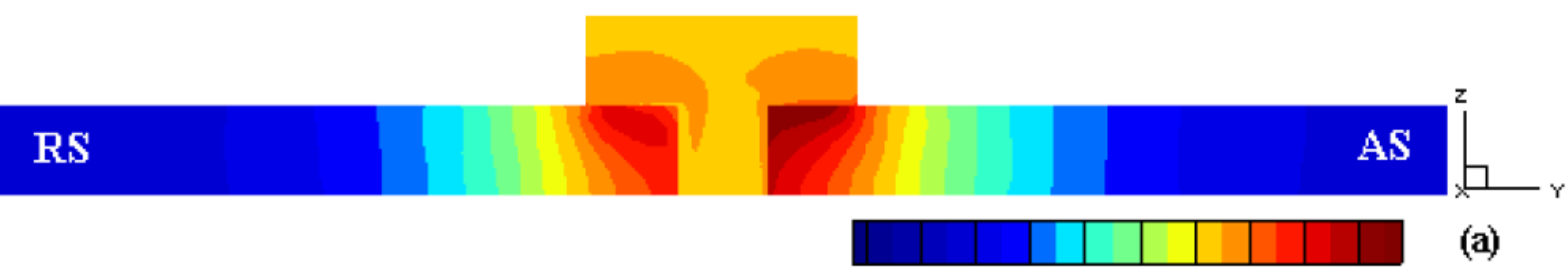

(a)

Temperature(K): 300360420480540600660720780840

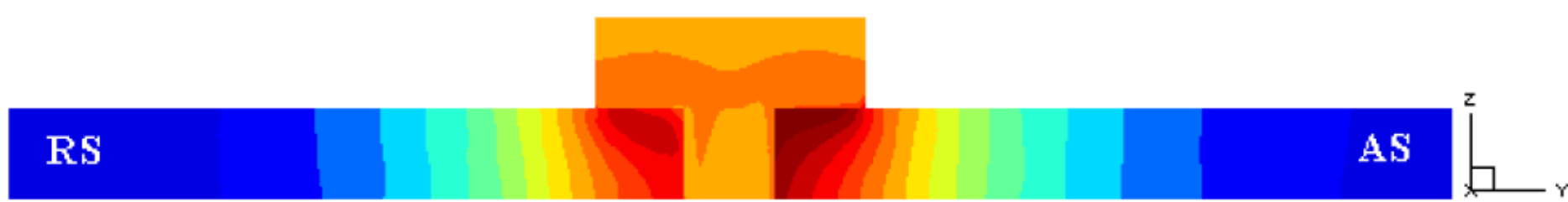

Temperature (K): 300360420480540600660720780840

(b)

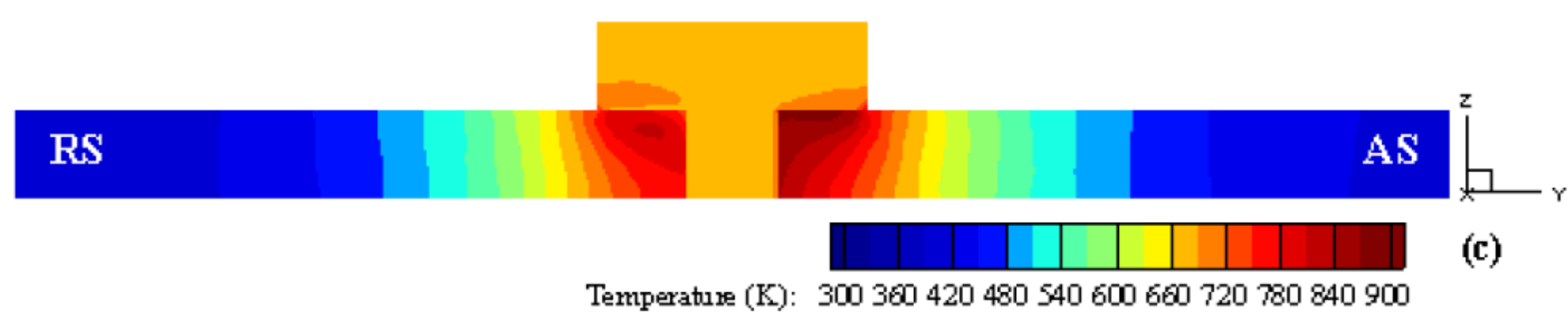

Figure 6

Cross-sectional temperature contours at the $x=0$ for the rotational speeds of a) $720, b) 920$, and c) 1120 $\mathrm{rpm}$. The welding speed is $0.002 \mathrm{~m} / \mathrm{s}$. 


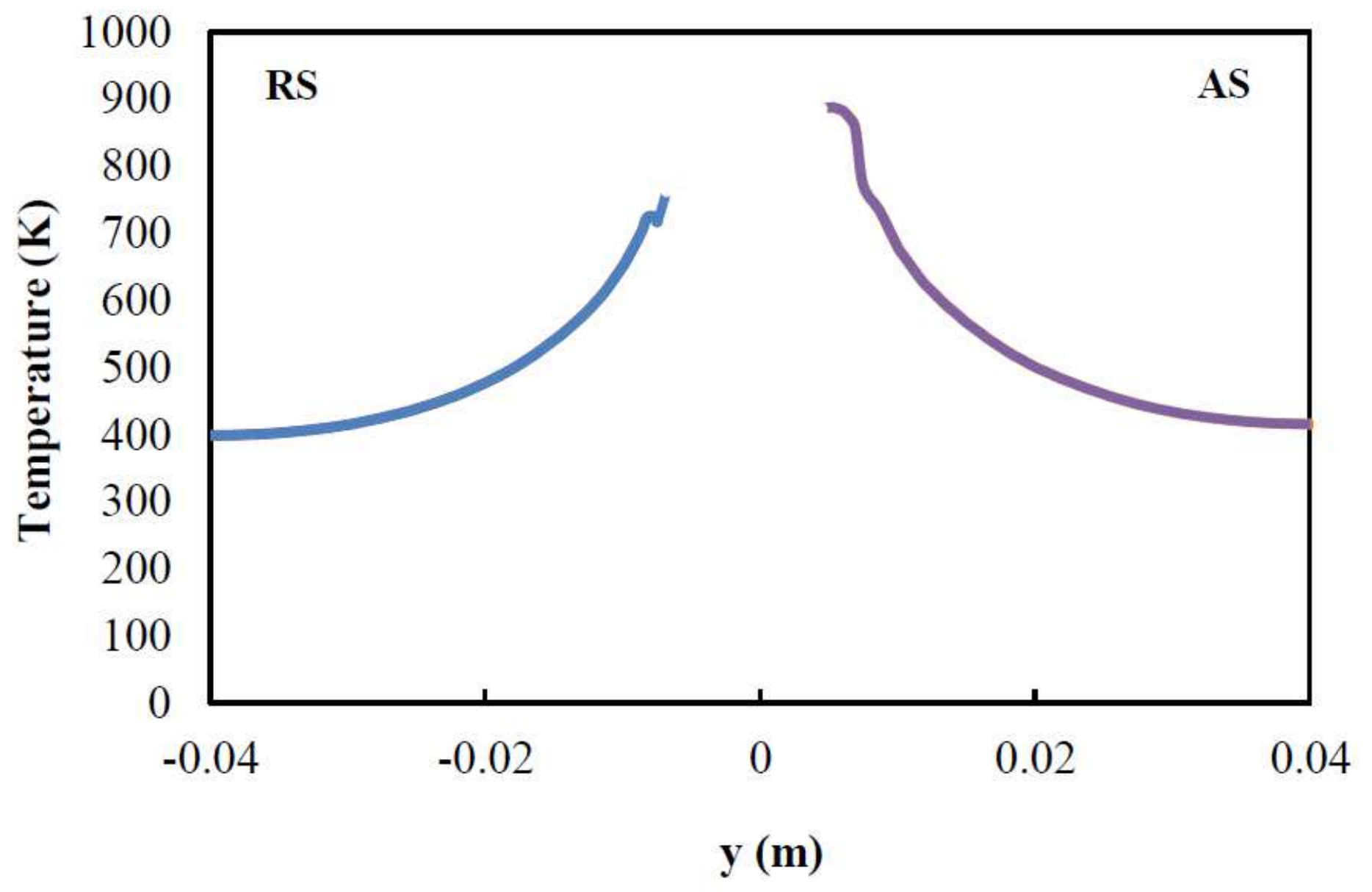

Figure 7

Calculated values of temperature at $z=0$ and $x=0$. The rotational speed is $1120 \mathrm{rpm}$, and the welding speed is $0.002 \mathrm{~m} / \mathrm{s}$.
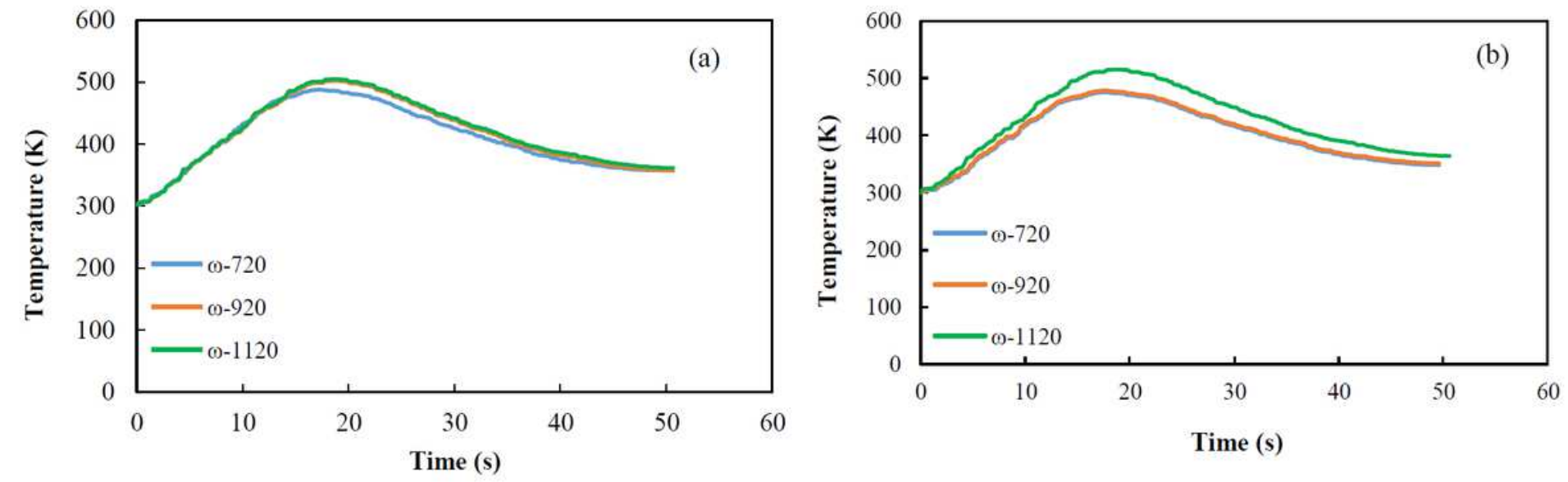

Figure 8

Calculated temperature-time graphs at the middle of the workpiece $(z=0.025)$ for rotational speeds on the a) AS and b) RS. The welding speed is $0.002 \mathrm{~m} / \mathrm{s}$. 

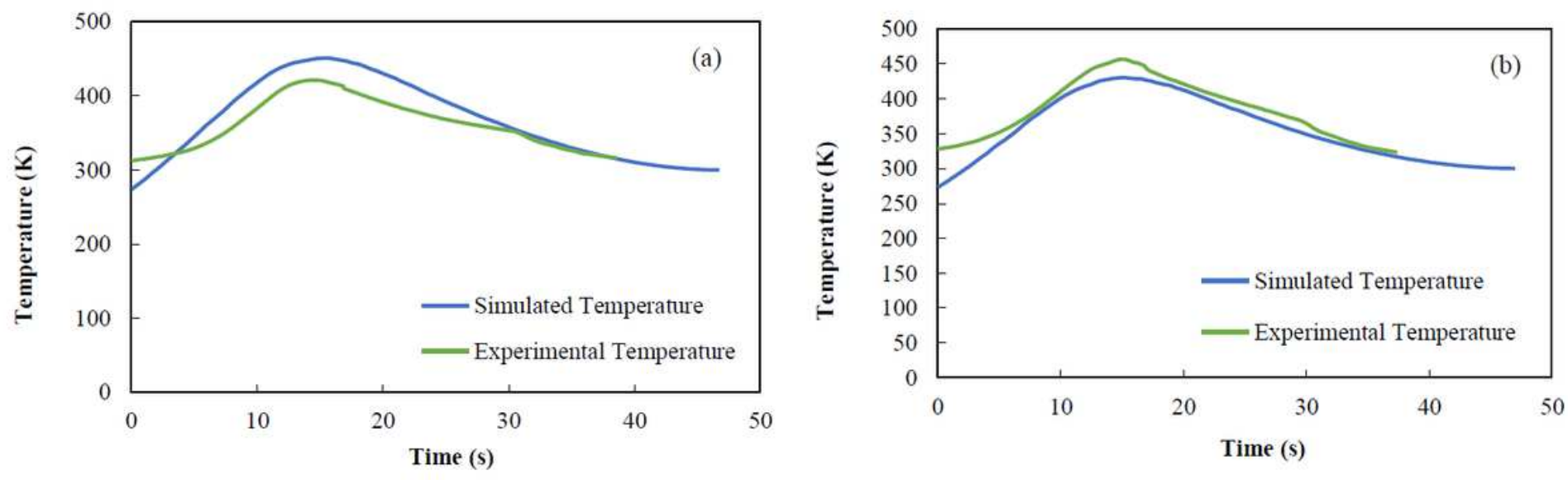

\section{Figure 9}

The predicted and experimental thermal cycles comparison for the sample welded under the rotational speed of $1120 \mathrm{rpm}$ and the welding speed of $0.002 \mathrm{~m} / \mathrm{s}$ a) on the AS, b) on the RS
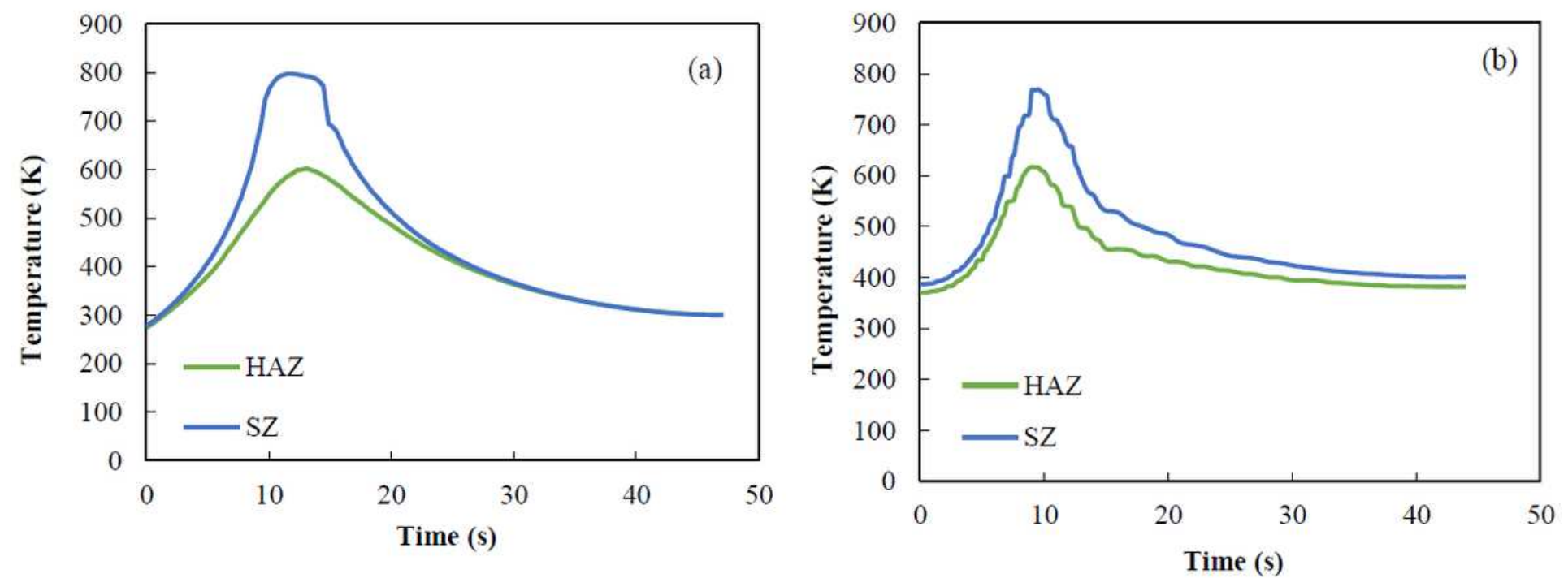

\section{Figure 10}

Thermal cycles $a)$ at the AS and $b$ ) at the RS, on the top surface of the workpiece ( $z=0)$. The welding speed is $0.002 \mathrm{~m} / \mathrm{s}$, and the rotational speed is $1120 \mathrm{rpm}$.

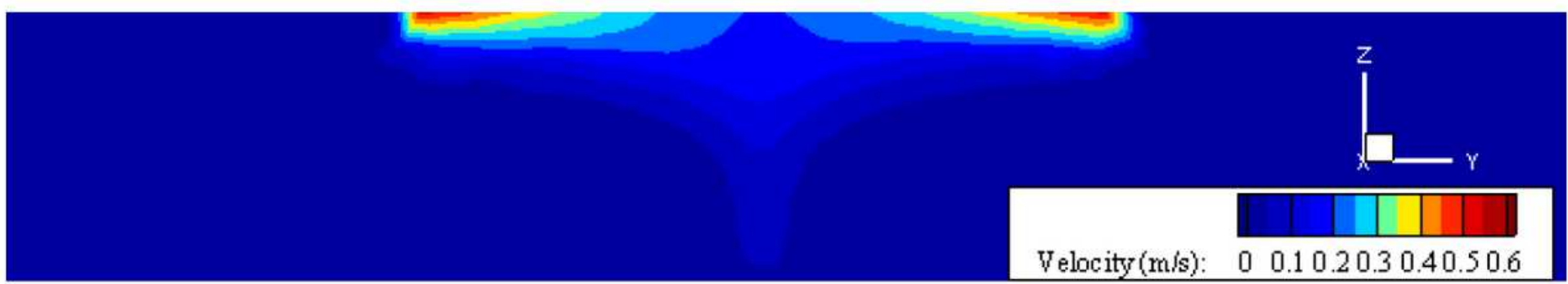


The velocity contour in the workpiece cross-section $(x=0.0026)$. The welding speed is $0.002 \mathrm{~m} / \mathrm{s}$, and the rotational speed is $1120 \mathrm{rpm}$.
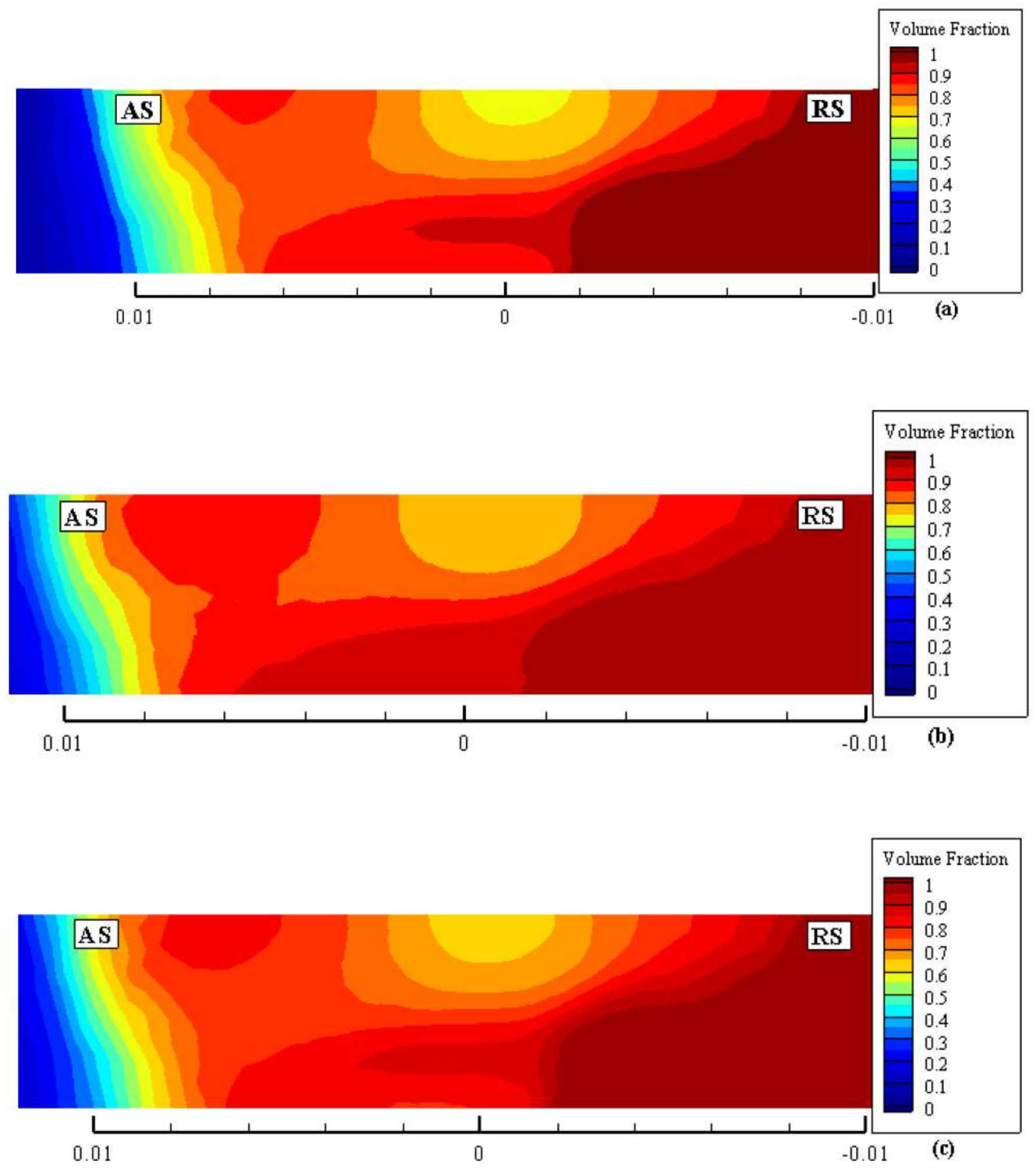

Figure 12

Volume fraction contours of AA6061 aluminum alloy at the workpiece cross-section. The rotational speed is a) $720 \mathrm{rpm}, \mathrm{b}) 920 \mathrm{rpm}, \mathrm{c}) 1120 \mathrm{rpm}$. The welding speed is $0.002 \mathrm{~m} / \mathrm{s}$. 


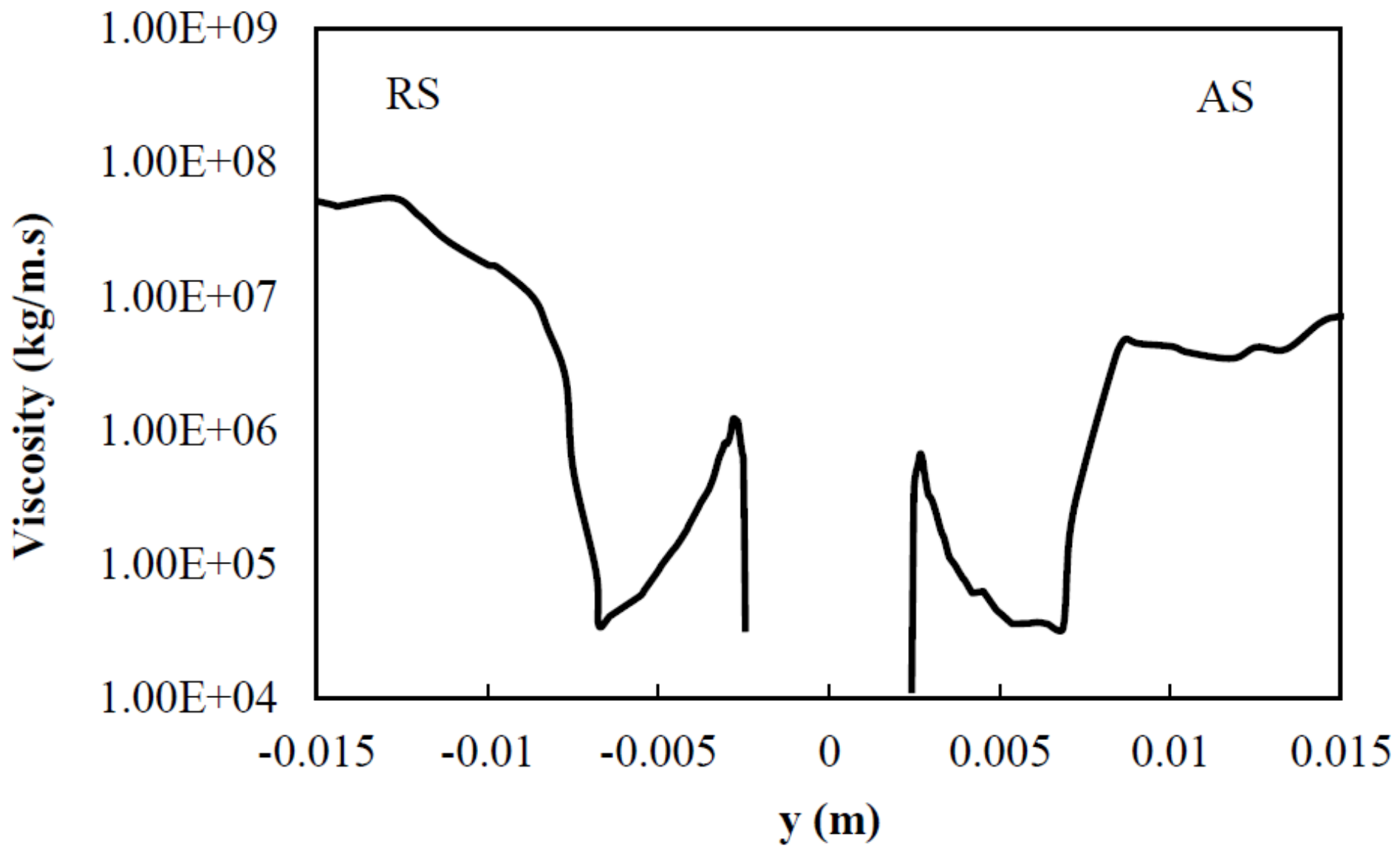

Figure 13

The viscosity magnitude at the cross-section of the workpiece $(z=x=0)$ as a logarithm to base 10 . The welding speed is $0.002 \mathrm{~m} / \mathrm{s}$, and the rotational speed is $1120 \mathrm{rpm}$. 